\title{
ESTELA ANTROPOMORFA CON INSCRIPCIÓN IBÉRICA DEL MAS DE BARBERÁN (NOGUERUELAS, TERUEL)
}

\author{
POR \\ FERRAN ARASA e ISABEL IZQUIERDO \\ Departament de Prehistòria i Arqueologia, Universitat de València \\ Domingo Fletcher Valls \\ in memoriam
}

\section{RESUMEN}

Presentamos el estudio de una pieza apenas conocida en el conjunto de estelas ibéricas con decoración figurada y epigrafía. Se trata de la estela hallada en el yacimiento del Mas de Barberán, en el término de Nogueruelas (Teruel), junto al límite con la localidad castellonense de Cortes de Arenoso. Reflexionamos sobre su morfología antropomorfa, su iconografía - el disco-coraza- y el epígrafe inciso que presenta.

\section{SUMMARY}

The subject of this paper is a little known Iberian gravestele from Nogueruelas (Teruel). The find-spot, the Mas de Barberán, is close to the boundary with Cortes de Arenoso (Castellón). The piece is one of a class of stelai charactised by figurative decoration and an inscription. The discussion focusses on the anthropomorphic shape of the piece, its iconography - the disk-cuirass-, and the inscription.

El municipio de Nogueruelas ${ }^{1}$ está situado al SE de la provincia de Teruel, en el límite con la de Castellón (fig. 1). Hacia el $\mathrm{O}$ es colindante con el término municipal de Mora de Rubielos, y hacia el E con el de Cortes de Arenoso (Castellón). Se encuentra al $\mathrm{S}$ de la Sierra de Gúdar, un macizo constituido fundamentalmente por materiales cretácicos, en cuyo extremo meridional se alcanzan alturas superiores a $1.800 \mathrm{~m}$ donde afloran las calizas aptenses; en esta dirección el límite de este gran abombamiento viene definido por la fosa de Rubielos de Mora, que da paso a la depresión de Sarrión (Simón, 1984, 113-116).

I En la Carta Arqueológica de Teruel no aparece mencionado ningún yacimiento del término municipal de Nogueruelas (Atrián et alii, 1980), aunque en la actualidad está siendo prospectado por J. Ibáñez, colaborador del Seminario de Arqueología y Etnología de Teruel. El vecino término municipal de Mora de Rubielos ha sido prospectado de manera sistemática por el equipo dirigido por F. Burillo, fruto de cuyo trabajo es el estudio sobre el poblamiento ibérico (Perales, 1989).

\section{EL HALLAZGO}

El año 1959, en el segundo número de la revista que los descendientes de Cortes de Arenoso editaban en Valencia, Samuel Ventura, archivero ya fallecido, publicó un pequeño artículo en el que se describen algunos parajes de este municipio y de su vecino Nogueruelas (Ventura, 1959), a partir de una excursión realizada en el verano de 1957. Allí se describe minuciosamente la estela que aquí estudiamos, de la que se reproducen dos fotografías y se apunta una transcripción del principio del texto. Asimismo se indica que una "persona muy caracterizada" del Museo Paleontológico de Valencia había visto la pieza y la había calificado de muy importante $^{2}$. Este artículo aparece mencionado en un libro sobre la toponimia del Alto Mijares y Alto Palancia, donde se indica que la estela se encontraba depositada en el Museo de Teruel (Nebot, 1991, 56).

La estela fue encontrada por J. Sanahuja en un yacimiento ibérico emplazado en tierras del Mas de Barberán, situado a $0,9 \mathrm{~km}$ del límite provincial con Castellón, que ocupa una estribación de la vertiente SO del Cabezo de la Cruz (1.710 m) que sirve de hito en la división provincial. Se trata de un espolón rocoso orientado N-S cuya cima alcanza una altitud superior a los $1.340 \mathrm{~m}$. A sus pies, en dirección $\mathrm{S}$, se extiende una pequeña llanura llamada el Plano que está cruzada por el Barranco del Campillo. Es accesible por el $\mathrm{N}$ y por el $\mathrm{E}$, aunque en este lado la pendiente es muy pronunciada, mientras que por el $\mathrm{O}$ y por el $\mathrm{S}$

\footnotetext{
${ }^{2}$ Consultados nuestros colegas del Museo de Teruel, nos comunicaron que no tenían conocimiento de su existencia, por lo que encaminamos nuestras gestiones hacia el ayuntamiento de Cortes de Arenoso, cuyo alcalde, J. Mata, nos comunicó que la estela se encontraba en la población, en cuyo ayuntamiento se custodia en la actualidad. La teniente de alcalde P. Tomás nos acompañó al lugar del hallazgo y nos ha dado las máximas facilidades para su estudio. A todos ellos les expresamos desde aquí nuestro más sincero agradecimiento.
} 


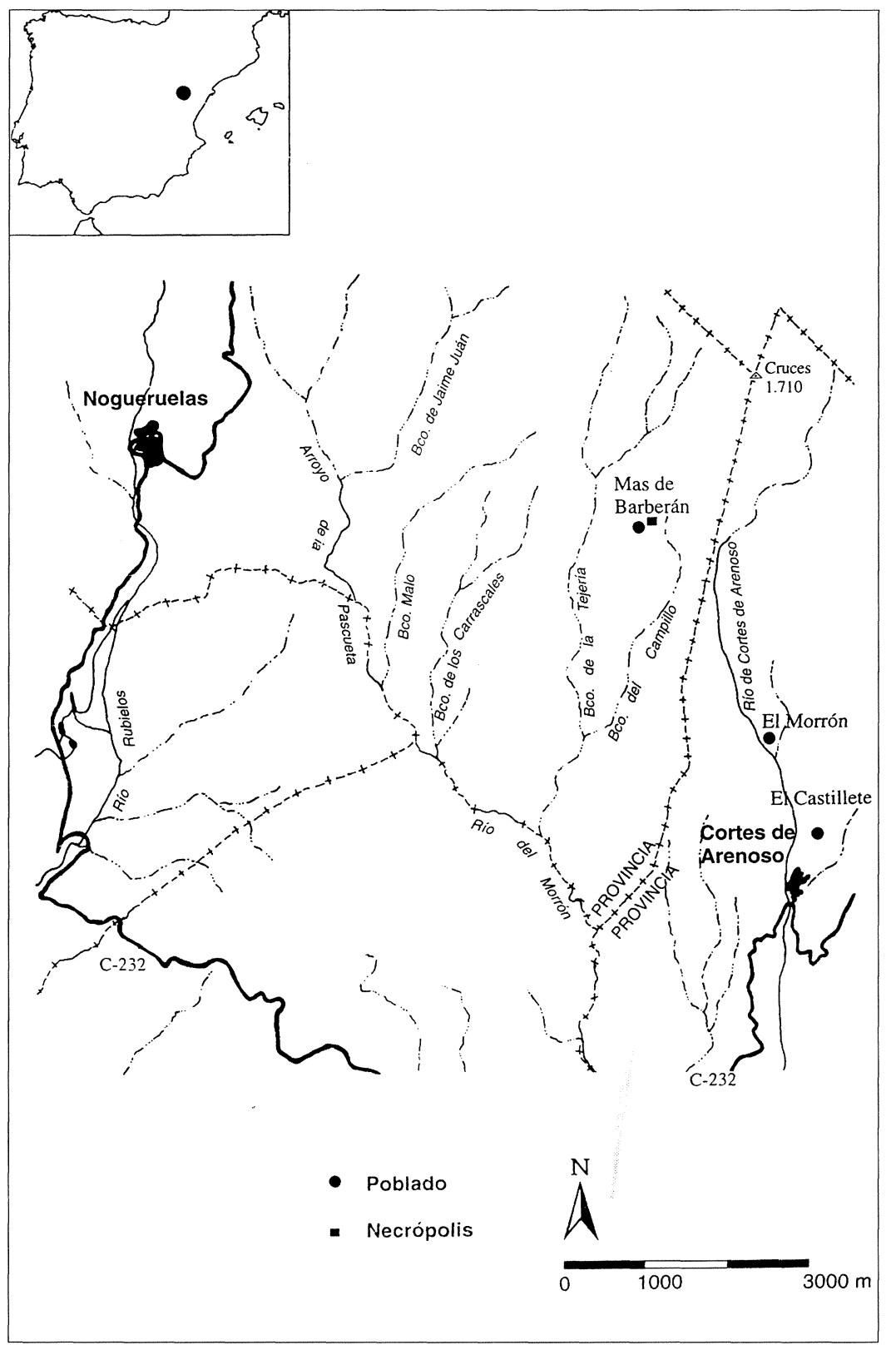

Fig. 1.-Localización del poblado y la necrópolis del Mas de Barberán (Nogueruelas, Teruel) sobre el M.T.N., hoja núm. 591 (28-31), Mora de Rubielos (Teruel), a escala 1:50.000.

paredes rocosas lo hacen completamente inexpugnable. Las características de su emplazamiento y el hecho de que el terreno descienda en altitud hacia el $\mathrm{S}$, hacen de este lugar una verdadera atalaya que permite un amplio control visual en esta dirección. El asentamiento ibérico más próximo, Los Morrones (1.140 $\mathrm{m})$, situado a $3,1 \mathrm{~km}$ hacia el SE en el término municipal de Cortes de Arenoso, resulta visible desde este lugar, como también lo es el del Castillete $(1.080 \mathrm{~m})$, situado a $4,4 \mathrm{~km}$ en la misma dirección.

$\mathrm{El}$ asentamiento ocupa la parte más alta del espolón y conserva restos de fortificaciones en el extremo $\mathrm{N}$ donde tal vez existiera una torre- y en el lado E. Adopta una forma estrecha y alargada, adaptado a la topografía. Se conservan restos de algunas construcciones que se distribuyen de forma escalonada por la ladera E. Los materiales cerámicos, muy fragmentados, son típicamente ibéricos. Algunos fragmentos de cerámica fabricada a mano podrían corresponder a una primera ocupación en la Edad del Bronce o el Hierro Antiguo. Algunos fragmentos de cerámicas romanas, como un pequeño fragmento de campaniense $\mathrm{B}$ tardía y un pivote de ánfora encontrado en las proximidades, confirman su perduración al menos hasta principios del siglo I a.C.

A unos $200 \mathrm{~m}$ en dirección NE, en la otra vertiente del pequeño barranco que se forma por este lado del espolón, se ha localizado la necrópolis, muy destruida por la erosión. Los restos encontrados son algunos fragmentos de cerámica fabricada a torno, pequeños fragmentos de huesos calcinados y escasos trozos de bronce y hierro muy oxidado. En algunos casos estos materiales aparecen concentrados en áreas reducidas que deben corresponder a una o más urnas y sus ajuares, entre los que no encontramos ningún fragmento de cerámica de importación. Recientemente se ha recuperado un lote interesante de armamento ibérico que formaba parte de los ajuares de las tumbas - espadas, lanzas, puñal, etc.- , cuyo estudio estamos preparando (Izquierdo, en prensa). Muy posiblemente la estela debe proceder de esta necrópolis, aunque cuando se dio a conocer en 1959 ya 
debía haber sido trasladada desde su lugar de hallazgo. Según se nos comunicó, la estela estuvo hincada en una grieta de la roca en la cima del asentamiento ibérico, aunque no consideramos que éste pudiera haber sido su emplazamiento original.

\section{DESCRIPCIÓN DE LA PIEZA ${ }^{3}$}

La estela antropormorfa del Mas de Barberán (figs. 2 y 3) presenta una morfología rectangular, alargada, y una sección muy recta, prismática y estrecha. Sus dimensiones generales aparecen detalladas en la tabla núm. 1. Una de las caras mayores de la estela - la cara principal- está alisada, decorada y muestra una inscripción, mientras que el dorso se halla únicamente desbastado, sin alisar. Las caras laterales están ligeramente alisadas, poco cuidadas. Son muy evidentes los efectos de la exposición y meteorización de la pieza, que han erosionado y alterado notablemente sus superficies.

\begin{tabular}{|c|c|c|c|}
\hline Dimensiones (en cm) & Máxima & Parte superior & Parte inferior \\
\hline Altura & 135,5 & - & - \\
\hline Anchura & 41 & 18 & 29,5 \\
\hline Profundidad & 18,5 & 13 & 15,5 \\
\hline
\end{tabular}

Tabla 1.-Dimensiones generales de la estela del Mas de Barberán (Nogueruelas, Teruel).

La estela está tallada en piedra arenisca de color amarronado, con algunas vetas de tonalidades que oscilan del rojo oscuro al negruzco, de textura compacta y dura, aunque granulosa, de procedencia posiblemente local. En ocasiones, la conformación del propio material pétreo, que se dispone a modo de capas horizontales, más o menos paralelas, apreciables sobre todo en las caras laterales, podría confundirse con los recorridos del instrumental utilizado en la talla de la pieza. En este sentido, con relación a la técnica de labra y el acabado de la estela, en el extremo superior del lateral izquierdo se observan diversas huellas del cincel empleado, de filo recto, estrecho y boca curva de $6 \mathrm{~mm}$ de anchura y $2 \mathrm{~mm}$ de profundidad. También es posible aventurar, a través de la sección de la decoración incisa, la utilización de un punzón de boca curva que genera suaves incisiones de 2 $\mathrm{mm}$ de anchura y profundidad. No se aprecia en la actualidad indicio alguno de policromía.

La pieza fue concebida para ser observada frontalmente por la cara principal, dotada de decoración y epígrafe. El desarrollo de esta cara se divide en tres partes principales: la inferior, de aproximadamente $0,5 \mathrm{~m}$ de altura, sin decoración y tan sólo desbastada; la central, con un módulo similar, decorada mediante la técnica de la incisión, donde aparecen figurados lateralmente los hombros, parte más

\footnotetext{
${ }^{3}$ Queremos expresar nuestro agradecimiento a todos los colegas que, con sus pacientes lecturas e interesantes consejos, han ayudado de manera decisiva en la preparación de este artículo: a los compañeros del Departamento de Prehistoria y Arqueología de la Universitat de València, C. Aranegui, C. Mata, J. Pérez Ballester y P. P. Ripollès; así como a R. Olmos, F. Quesada, J. Untermann, J. Velaza y J. de Hoz.
}

destacada, donde se representa un disco-coraza en posición central y el campo epigráfico, pautado por cinco líneas-guía; finalmente, la parte superior, de menores dimensiones, en torno a $35 \mathrm{~cm}$ de altura, carece de decoración y se va estrechando progresivamente.

La estela, que representa un personaje masculino armado, obvia la labra de la cabeza. Su fisonomía está implícita en el diseño de la propia estela. Su cara superior, en una vista cenital, es plana y se halla alisada irregularmente; presenta, además, una fina línea incisa horizontal de $10 \mathrm{~cm}$ de longitud y $2 \mathrm{~mm}$ de anchura, que corre paralela a la anchura de la parte anterior de la pieza, enmarcándola. Los hombros, ligeramente asimétricos, se inician aproximadamente a los $35 \mathrm{~cm}$ de altura de la parte superior de la estela; se encuentran levemente alisados y presentan forma redondeada, con una anchura máxima de $41 \mathrm{~cm}$. Sobre ellos se representan las correas que sujetan los discos-coraza ibéricos. Estas defensas se colocaban en el centro del torso y la espalda. En el ejemplo que estudiamos, tan sólo se labra el disco delantero o pectoral, que cuelga de los correajes, mal conservados. En la parte derecha se aprecia bien una correa lisa de $3,8 \mathrm{~cm}$ de anchura, que presenta una ligera curvatura cóncava. Un detalle de la labra de este elemento es la existencia de una línea incisa de $1,4 \mathrm{~cm}$ de longitud, que no tiene continuidad, junto a la línea que figura el extremo superior de la correa. El primer tramo inciso podría ser interpretado como un error que es posteriormente corregido. En la parte izquierda, muy erosionada y mal conservada, con parte de la decoración perdida, se observa tan sólo el inicio del correaje. 


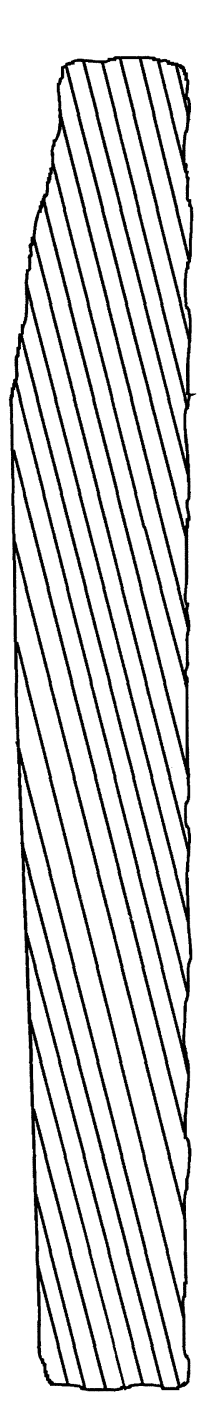

Sección

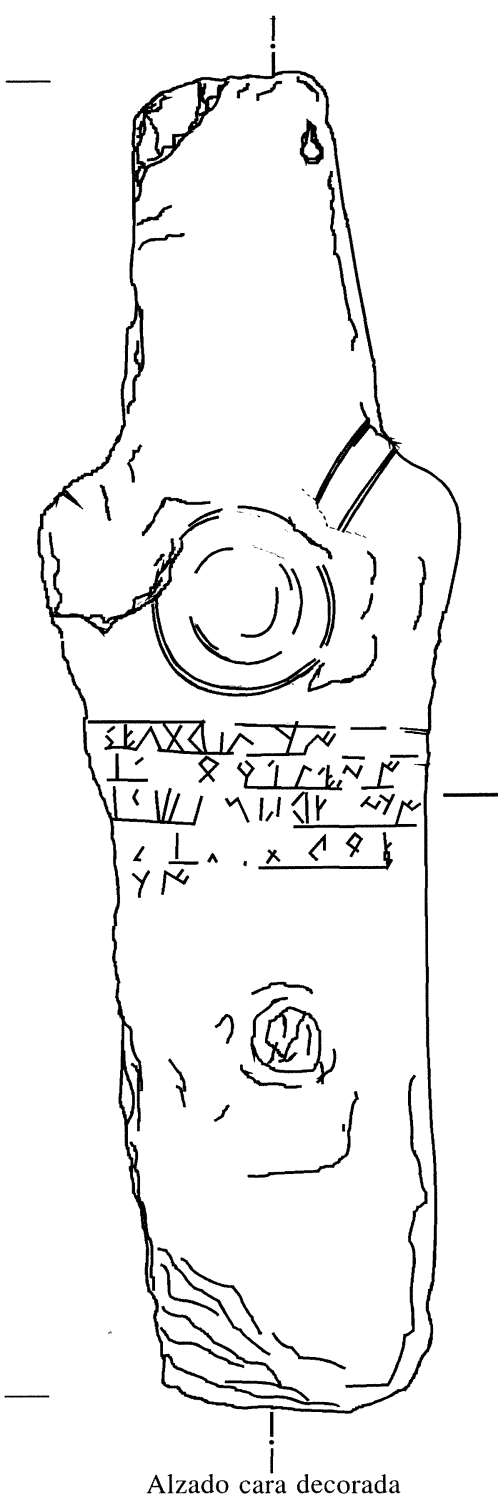

Alzado cara decorad

bastante mal conservada, de cinco renglones, adaptada a la anchura del cuerpo de la estela -34 / 32 $\mathrm{cm}$ - A $62 \mathrm{~cm}$ de altura, se inicia el campo epigráfico que está preparado, pues se aprecia un alisado de la superficie. El surco de las cinco líneas-guía, ejecutadas con un punzón de boca con sección "en $\mathrm{v}$ ", es de $1 \mathrm{~mm}$ de anchura y su profundidad no lle-

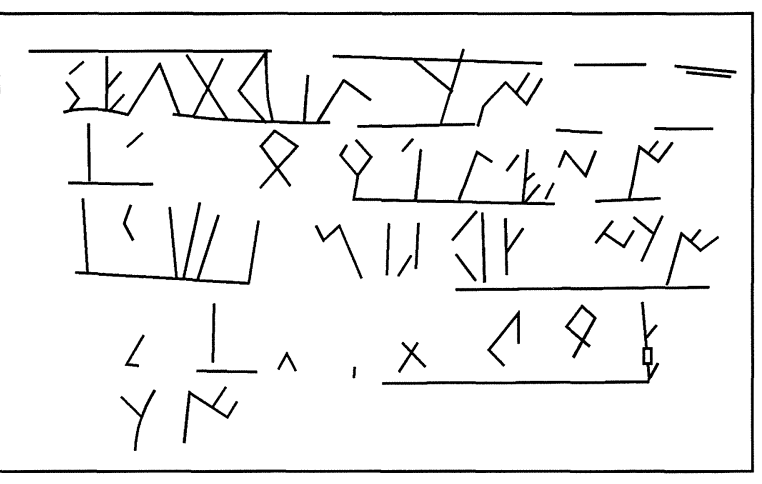

Epígrafe



Fig. 3.-Estela ibérica del Mas de Barberán (Nogueruelas, Teruel). Alzado de la cara principal con decoración y epigrafía (foto, autores) 
ga a $1 \mathrm{~mm}$. En el tercio inferior de la pieza, el peor tratado y conservado, a $90 \mathrm{~cm}$ de altura desde la parte superior, se observa una concavidad de $6 \mathrm{~cm}$ de diámetro, de aspecto natural, consecuencia probablemente del trasiego de la pieza desde su ubicación original, aunque no se descarta una intencionalidad en su formación. La parte inferior de la estela, muy erosionada, que originalmente iría clavada en tierra, únicamente se halla desbastada.

En definitiva, en esta estela antropomorfa ibérica se representa, esquemáticamente, un personaje masculino armado, que porta un elemento defensivo, el disco-coraza. Se trata de la imagen de un guerrero ibérico con inscripción. La técnica y el estilo, como es evidente, son bastante simples. Noy hay grandes alardes por parte del artesano en la factura de la labra. Las superficies son totalmente planas, sin atisbo alguno de realzar volúmenes. No existe tampoco una minuciosidad descriptiva. La verticalidad de la estela, de formas muy geométricas, queda rota, en primer lugar, en su parte central por el gran disco pectoral y los hombros; en segundo lugar, por la horizontalidad del campo epigráfico. Estamos ante una pieza que se inscribiría en un hipotético marco de segundo orden en el conjunto de la estatuaria ibérica si atendemos a su calidad técnica y estilo, atribuible a un taller local.

\section{ESTUDIO DE LA ESTELA}

\subsection{Morfología y tipología}

La particular morfología de esta pieza, su decoración y la inscripción que muestra permiten compararla con las diversas series de estelas ibéricas (Izquierdo, 1997, 66-77), y de manera destacada, la de las denominadas estelas antropomorfas o estatuas-estela, cada vez más rica; por otra parte, desde el propio territorio del hallazgo nos detendremos en la serie de estelas bajoaragonesas decoradas, así como en las epigráficas ${ }^{4}$.

En cuanto a la primera serie, contamos con distintos ejemplos, como la estela de La Serrada, hallada en la cercana localidad de Ares del Maestre (Castellón), recientemente estudiada (Izquierdo y Arasa, en prensa b). Se trata de un ejemplar acéfalo, de menores dimensiones que el que presentamos en esta ocasión, anepígrafo y con figuración femenina. La dama que aparece labrada en esta estela está enjoya-

\footnotetext{
${ }^{4}$ Esperamos la publicación de un trabajo de conjunto sobre las diversas series de estelas ibéricas, a la vista de los nuevos hallazgos, sus precedentes peninsulares y paralelos mediterráneos (Izquierdo y Arasa, en prensa a).
}

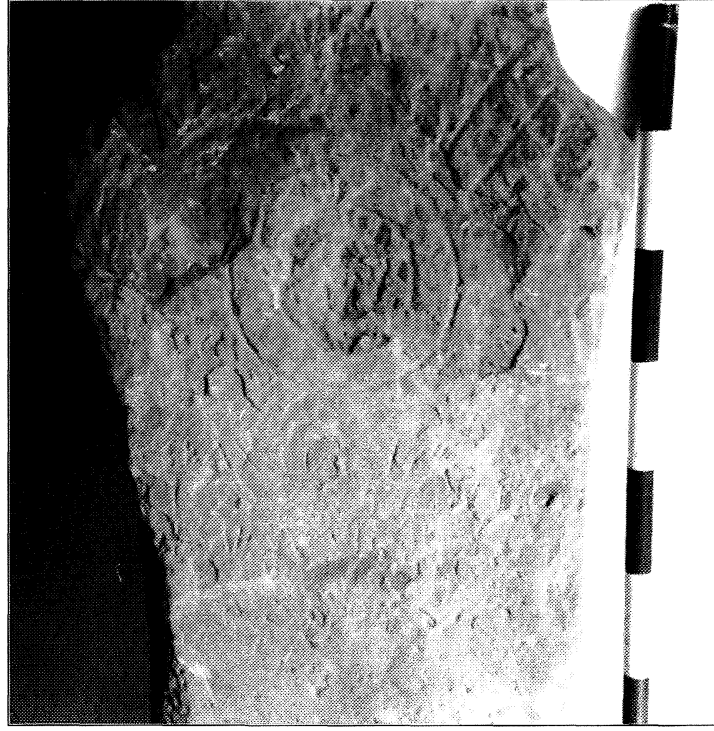

Fig. 4.-Detalle del disco-coraza e inscripción de la estela de Nogueruelas (foto, autores).

da y ataviada con sus mejores galas, a la manera ibérica. Por otra parte, en el territorio contestano hemos de destacar la estela antropomorfa masculina (fig. 5), también acéfala, de Altea la Vella (Alicante), publicada por Morote (1981) y posteriormente recogida por Lucas, Ruano y Serrano (1991, 309-310), a propósito de la estela de Espejo. Sus dimensiones se aproximan más a la del Mas de Barberán $(108 \mathrm{~cm}$ de altura conservada $\times 29 \mathrm{~cm}$ de anchura y $20 \mathrm{~cm}$ de profundidad). Representa un guerrero, del que se aprecian los hombros, el cuello, el escote "en v" de su túnica, el cinturón, e incluso los pies. El armamento que aparece labrado es significativo: un cuchillo afalcatado en su cara frontal y una espada de antenas en una de sus caras laterales. La estela de Altea ha sido considerada un unicum en la estatuaria ibérica, sin relación con las conocidas estelas del Suroeste, ni con las tardías del periodo iberorromano. Sus paralelos se han establecido generalmente con estelas extrapeninsulares, concretamente con la serie daunia, que continúa las tradiciones del Bronce final y Hierro inicial en esta región itálica ${ }^{5}$.

En Espejo (Córdoba) fue localizada la estela publicada por Lucas, Ruano y Serrano (1991) que se caracteriza por su configuración antropomorfa, similar a las piezas comentadas de Ares del Maestre

\footnotetext{
5 Para esta serie, $c f$. Nava (1980 y 1984; De Juliis, 1988 80 o más recientemente, Pontrandolfo, Mugione y Salomone, 1997). Asimismo, autores como Quesada (1997, I, 201) han establecido paralelos con las estelas de Guardiagrele (Chieti) o Filetto (Lunigiana). Se trata de piezas de una gran simplicidad que no pueden hacerse derivar unas de otras.
} 

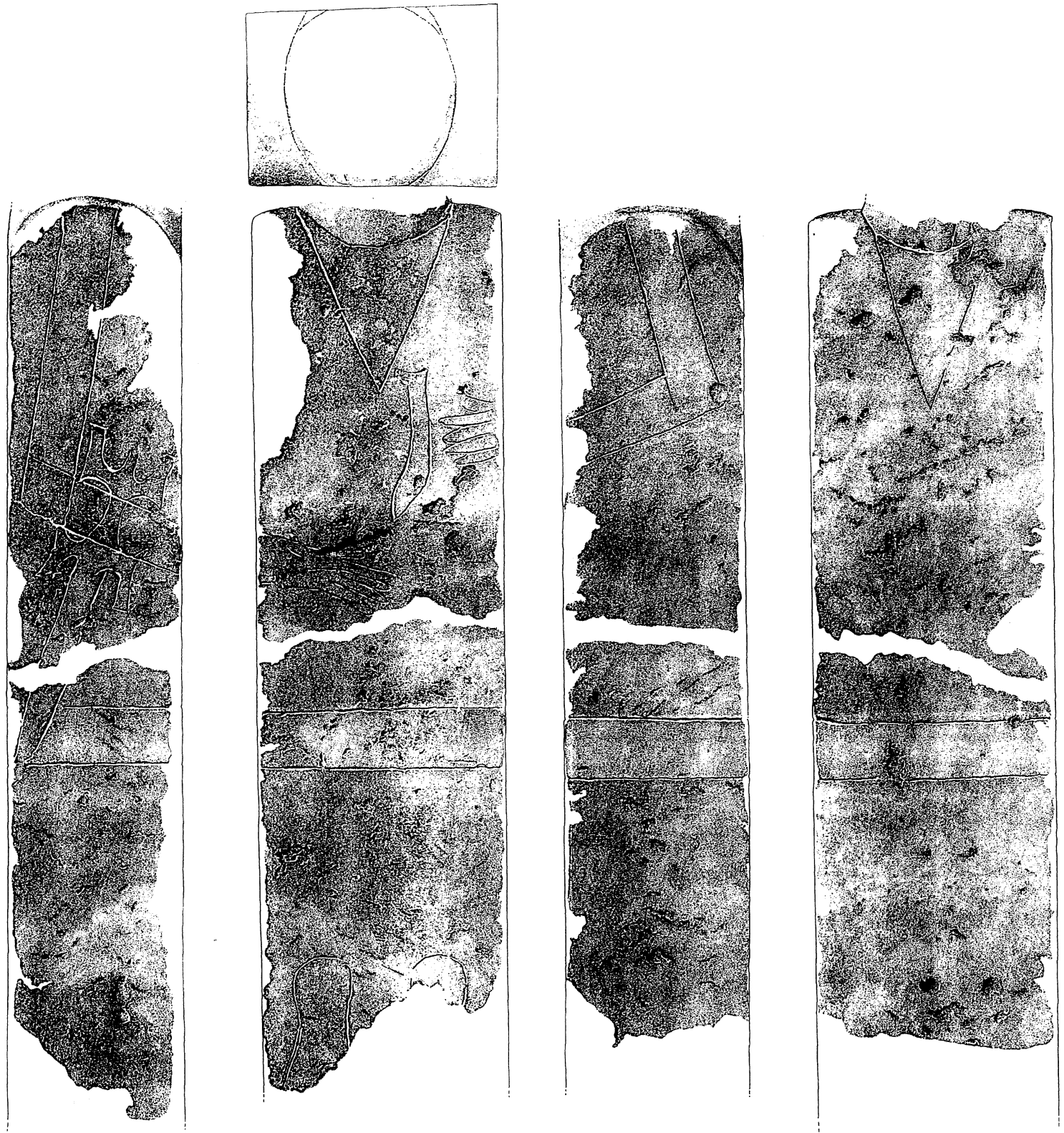

Fig. 5.-Estela ibérica de Altea la Vella (Alicante) (dibujo, J. Gisbert).

y Altea la Vella, aunque muy distinta en otros aspectos. Conserva $43 \mathrm{~cm}$ de altura y muestra a una dama ibérica, con collares y adornos en su túnica. Como paralelos de esta pieza se han señalado ciertas esculturas de Torreparedones, Cerro de los Santos, el conjunto votivo de Torrebenzalá y algunas esculturas cordobesas, una de las cuales - figura masculina del Cerro de los Molinillos de Baena- podría incluirse en la serie de estelas antropomorfas ${ }^{6}$.

\footnotetext{
${ }^{6}$ Un estado de la cuestión sobre el tema de las estelas antropomorfas peninsulares, de gran tradición desde época pre-
}

La serie de estatuas-estela en la cultura ibérica agrupa piezas muy distintas entre sí, contemplando la representación de ambos géneros: personajes masculinos, que evocan el mundo del guerrero, y personajes femeninos, las damas. Presentan rasgos compartidos en su estructura general, figuración antropomorfa y escasos alardes técnicos, pero mani-

histórica, completa el citado trabajo de Lucas, Ruano y Serrano (1991). Pueden verse al respecto, asimismo, Almagro Basch (1966 y 1974), Almagro Gorbea (1993), Barceló (1988) y Galán (1993), entre otros. 
fiestan asimismo diferencias en sus dimensiones, forma y decoración. Su localización geográfica, a su vez, las sitúa en territorios muy distintos y alejados entre sí. Se trata de piezas singulares que revelan un marcado interés por representar determinadas categorías de estatus y género a través de atributos específicos y caracterizadores, como el armamento o las joyas y la indumentaria. La precisión en los detalles anatómicos o la calidad en la labra son cuestiones secundarias. Estamos ante talleres o manos evidentemente distintas, que se caracterizan por un estilo poco cuidado, más bien tosco, y el trabajo con unos modelos idealizados, muy difundidos a juzgar por la localización de las piezas, en los que la sociedad ibérica se reconoce.

Otra cuestión que se plantea es la cronología. La estela de Altea podría fecharse entre los siglos v o IV a.C. (Morote, 1981). La tipología del armamento representado y el contexto ceramológico asociado así parecen indicarlo. Para la pieza de Espejo se ha propuesto una fecha insegura de finales del siglo IV a.C., en función de su carácter esquemático y la conjunción de tradición antigua y asimilación de influjos externos (Lucas, Ruano y Serrano, 1991, 318). La estela de La Serrada correspondería a un momento intermedio entre la incorporación de las grandes damas al repertorio de la plástica ibérica que puede situarse desde mediados del siglo Iv o durante el siglo III a.C., y la serie de las estelas epigráficas, de cronología ya más tardía. En definitiva, nos enfrentamos de nuevo al complejo problema de la ausencia de contextos arqueológicos. No obstante, ciertos rasgos comunes a todas estas piezas y la presencia de la inscripción en la estela de Nogueruelas podrían indicar una datación quizás coetánea y tardía.

Desde otra perspectiva, en el propio territorio aragonés hemos de destacar la conocida e interesante serie de estelas decoradas con figuración, concentrada fundamentalmente en el Bajo Aragón ${ }^{7}$. Se tra-

\footnotetext{
${ }^{7}$ Dentro de su estudio sobre las estelas de los conventos cesaraugustano y cluniense, Marco (1978, 90-91) distinguía las piezas de cronología anteimperial, que constituían una minoría, de las de época plenamente imperial. Entre las primeras cabe destacar las estelas cántabras y su ámbito de influencia (Galdácano, Meñaca), las estelas con inscripción ibérica de Clunia y otras dentro del grupo burgalés (Iglesia Pinta y Lara), así como otros ejemplares aislados, cuya cronología se sitúa entre los siglos II y I a.C. Las estelas del Bajo Aragón se incluyen en este grupo y poseen en conjunto una datación del siglo II o de la primera mitad del siglo I a.C. Fueron objeto de diversos trabajos en el pasado, inicialmente por parte de Cabré (1915-1920), Bosch Gimpera (19151920) o Fernández Fuster (1951), hasta llegar a las publicaciones más recientes, entre otros, de Marco (1976 y 1978), Martín-Bueno y Pellicer (1979-1980) o Quesada (1994), sin ánimo de ser exhaustivos. En el reciente trabajo de Beltrán
}

ta de una serie que aparece concentrada en Teruel y Zaragoza, en las localidades de Alcañiz, Caspe, Chiprana, Calaceite, Cretas, Valderrobres y Valdetormo. Se ha supuesto la existencia de un foco central dentro del ámbito bajoaragonés, al N, en la ribera del Ebro (Chiprana, Caspe, etc.) y otro foco al SE, determinado por las piezas de Cretas y Valderrobres (Marco, 1976, 89-90). En especial, destaca el grupo de Alcañiz y Caspe, que engloba la mayor parte de las piezas conocidas, de fuerte personalidad. Jinetes y armas - lanzas y escudos-, además de escenas bélicas y motivos geométricos, componen su universo iconográfico particular ${ }^{8}$.

La tipología elaborada por Fernández Fuster y Marco viene a distinguir, en síntesis, entre las estelas con representaciones figuradas anepígrafas, con el tema de jinetes aislados o sobre supuestos enemigos vencidos, caballos, lanzas, medallones o rosetas; las estelas con iconografía y epigrafía en signario ibérico, con el tema recurrente de las armas y motivos geométricos; las estelas sin iconografía, sólo con elementos epigráficos; y, finalmente, las piezas consideradas como ecos de los pilares-estela de los siglos v y IV a.C., con epigrafía, donde se destaca el ejemplo excepcional de El Acampador de Caspe (Zaragoza). La estela de Caspe (figs. 6 y 7) es interesante por su morfología, iconografía, e incluso, según la hipótesis de algunos autores, por su posible relación con los pilares-estela ibéricos en lo que respecta a su forma y decoración (López Monteagudo, 1983, 264). La pieza fue estudiada en profundidad por Martín-Bueno y Pellicer (1979-1980). La parte conservada en la actualidad tiene una altura de $113 \mathrm{~cm}$ y $80 \mathrm{~cm}$ de anchura. Merece la pena detenernos en su iconografía: por un lado, el relieve con felino que remata la pieza, con las conocidas connotaciones simbólicas que posee; por otro lado, la decoración de armas -un scutum y tres caetrae-, elementos de prestigio de la panoplia ibérica, sin olvidar la inclusión de la larga inscripción, que cuenta con elementos nominales ${ }^{9}$. La cronolo-

sobre los iberos en Aragón aparece una buena síntesis de los hallazgos, su descripción, decoración, forma, dimensiones, contextos y cronologías (Beltrán, 1996, 175-183).

${ }^{8}$ Precisamente, las lanzas han sido definidas como el elemento más importante y personal de los que definen iconográficamente las estelas del Bajo Aragón (Marco, 1976, 83), interpretadas como la alusión al número de victorias o de enemigos vencidos por parte del difunto, según la visión tradicional de Cabré o Bosch Gimpera (1915-1920, 637-638) o como un elemento de índole escatológica, símbolo de la heroización del difunto (Marco, 1976, 85-86).

${ }^{9}$ Los primeros investigadores que dieron a conocer la pieza insistieron en la interpretación funeraria de la estela; la simbología del león, que la vincula con el mundo ibérico de la costa mediterránea; el registro con iconografía de escudos, sin entrar en la atribución de cada uno a un enemigo venci- 


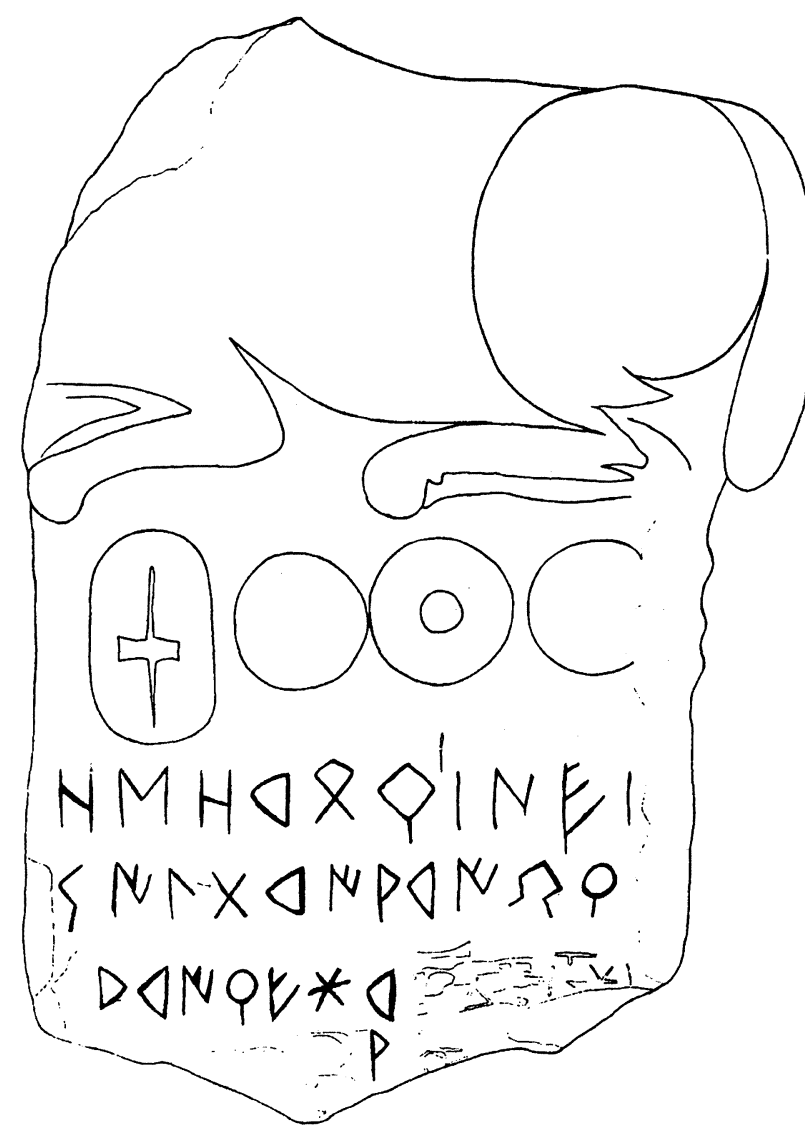

0

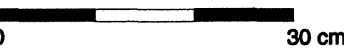

Fig. 6.-Estela ibérica de El Acampador (Caspe, Zaragoza), según Martín-Bueno y Pellicer, 1979-1980, fig. 1.

gía de este monumento se ha situado en el siglo II a.C., aunque algún autor ha considerado que es más adecuado fecharlo en un momento anterior (Beltrán, 1996, 183).

Otras piezas del ámbito bajoaragonés que recogió inicialmente Cabré (1915-1920, 630-633, figs. 439,440 y 442) y que merece la pena resaltar son las estelas de El Mas de Magdalenes, El Tossal de les Forques y El Mas de Pere de la Reina, todas procedentes de la localidad de Cretas (Teruel) (fig. 8), que muestran una decoración con discos y lanzas. En algunos casos - como en la de El Mas de Magdalenes-, se incluyen epígrafes incisos. Los grandes discos o círculos decorados, a veces con rosetas en su interior, son bien conocidos dentro de la

do, según las tesis clásicas de Cabré o Bosch, y la importancia de la gran inscripción ibérica que presenta (Martín-Bueno y Pellicer, 1979-1980).



Fig. 7.-Estela ibérica de El Acampador (Caspe, Zaragoza), según fotografía de Beltrán, 1996, fig. 176.

serie. En los ejemplos citados, además de otros como en una estela de Torre Gachero de Valderrobles (Teruel) (Atrián, 1979, 174, fig. 13), estos elementos aparecen en posición central con dos bandas cruzadas, dispuestas en aspa. La interpretación de estos motivos, en general, siguiendo a Marco (1974, 99-100), se sitúa entre su consideración bien como simples decoraciones, bien como estilizaciones relacionadas con la figura humana, o bien como símbolos astrales. Es esta última hipótesis la más difundida entre la investigación tradicional. Por nuestra parte, sin descartar el sentido dado a estas representaciones, podríamos aventurar otra lectura, concretamente, para el caso de los grandes discos. Resaltamos, en primer lugar, su posición central en la estela y su asociación con bandas cruzadas, decoradas en ocasiones, a modo de cintas. Los discos aparecen, asimismo, conjuntamente con puntas de lanza. Estas representaciones podrían figurar en realidad una defensa corporal o, más explícitamente, discos-coraza, con su característica disposición (v. infra). De este modo, lanzas y discos evocarían el mundo y los valores del guerrero en el soporte de la estela. 
La estela de Nogueruelas con figuración y epigrafía, se encuentra muy próxima al límite con la actual provincia de Castellón, que cuenta con buenos ejemplos de estelas ibéricas, tanto con epígrafes -en su mayor parte- como, de manera excepcional, sin ellos - recordemos el citado caso de La Serrada- Con respecto a las primeras, destacaremos las de Canet lo Roig (Fletcher y Giner, 1974), Alcalà de Xivert (Oliver, 1978), Benassal (Ballester, 1942, 132-133; Fletcher, 1985, fig. 44, Lám. XL), Cabanes (Esteve, 1989) o la de Bell-lloc (Arasa, 1989). En relación a su cronología, recientemente en distintos trabajos, autores como Oliver (1996), recogiendo las tesis de Maluquer, o Velaza (1993) señalan los siglos II y i a.C. (v. infra).

Pero, por otro lado, la proyección de la imagen del guerrero en una estela no es exclusiva del mundo ibérico. Podemos evocar, en este sentido, la singular estela antropomorfa celtibérica de Segura del Toro (Cáceres), hallada muy cerca de un gran verraco y varias estelas discoidales, características de este ámbito cultural. La pieza es de granito, de 109 $\mathrm{cm}$ de altura, y representa un guerrero armado con una espada de tipología singular. Existen, asimismo, otros muchos casos extrapeninsulares. No obstante, pensamos que la estela del Mas de Barberán encuentra sus mejores paralelos en las citadas series ibéricas de estatuas-estela, los ejemplos bajoaragoneses con epigrafía y figuración, así como las estelas epigráficas castellonenses no decoradas —éstos dos últimos grupos situados en territorios cercanos al del lugar de hallazgo de la pieza que aquí estudiamos-.

\subsection{Decoración: el disco-coraza}

El disco-coraza representado en la estela de Nogueruelas encuentra paralelos con otras esculturas ibéricas, así como con elementos metálicos de bronce y hierro documentados por el registro arqueológico, fundamentalmente de las necrópolis. La evidencia de la protección para el guerrero ibérico es escasa. Las corazas se hallan muy mal representadas en los realia de la panoplia ibérica porque, por un lado, en gran parte éstas debieron ser elaboradas con material orgánico y, por otro lado, por su carácter de exclusividad, pues parecen ser patrimonio de una minoría privilegiada (Quesada, 1997, II, 572). Además, las fuentes literarias, según ha visto Quesada (ibid., 582), tampoco ofrecen datos de gran interés al respecto. De un momento anterior, conocemos la estela del Cortijo de Gamarillas, adscrita al grupo de estelas extremeñas, estudiada por Almagro
Basch $(1974,8)$, donde sobre una figuración masculina fue interpretada la presencia de una coraza. Pero en general, la presencia de la coraza en la Protohistoria occidental mediterránea es bastante escasa, como ha señalado Chenorkian $(1988,219)$.

El disco-coraza ibérico (Kurtz, 1985 y 1991; Li1lo, 1986, 537-567; Ruano, 1987, II, 431-433; Quesada, 1989, 20-23, y 1997, II, 572-577) es un elemento defensivo que se utiliza para proteger el torso y la espalda del guerrero y, en ocasiones, los hombros. Parece clara su función defensiva, deducida básicamente a partir de los ejemplos elaborados en hierro. No obstante, diversos autores han atribuido a los discos de bronce un posible carácter ritual o ceremonial. Lo que parece seguro, y así lo evidencian las esculturas ibéricas, esencialmente las del Cerrillo Blanco de Porcuna, es su utilización en combate, ya sea éste real o simbólico (Negueruela, 1990). Los dos discos - pectoral y espaldar - se unen mediante correas que pasan sobre los hombros. Este sistema de sujeción se complementa con sendas correas que ciñen los costados por debajo de las axilas. Asimismo, los grandes discos pueden acompañarse de protecciones ¿orgánicas? en los hombros, axilas y espalda. El catálogo de piezas conocidas no es interpretado de la misma forma por los distintos autores. Los ejemplos procedentes del área de la Meseta ${ }^{10}$, a pesar de la importancia de esta tradición en la literatura especializada, son mucho menos abundantes que los del área ibérica - Cabecico del Tesoro de Verdolay-La Alberca (Murcia), La Serreta (Alcoy, Alicante), La Solivella (Alcalà de Xivert, Castellón), El Puig de Benicarló (Castellón), La Oriola (Tarragona) o Granja Soley (Barcelona) ${ }^{11}$ -

Desde la iconografía, las esculturas ibéricas que presentan este tipo de defensa pasiva son los guerreros núms. 1, 2, 3 y 4 del Cerrillo Blanco de Porcuna (Jaén; González Navarrete, 1987, 47-52 y 71-74; Ne-

${ }^{10}$ En la tumba núm. 350 de la necrópolis de La Osera (Chamartín de la Sierra, Ávila) se documentaron dos discos de hierro de $26 \mathrm{~cm}$ de diámetro (Kurtz, 1985, 20; Negueruela, 1990, 147; Quesada, 1997, II, 572). Igualmente, en diversas tumbas - entre ellas la A y B-de Aguilar de Anguita (Guadalajara) se documentó un número indeterminado de entre 3 y 9 discos de bronce, algunos de 18 y $19 \mathrm{~cm}$ de diámetro (Kurtz, 1985, 19; Negueruela, 1990, 143-145; Quesada, 1997, II, 573)

11 En la tumba núm. 400 del Cabecico del Tesoro se hallaron dos discos, doblados e inutilizados en una gran urna, de $25 \mathrm{~cm}$ de diámetro (Nieto, 1944, 171, lám. 23), que presentan puntos en común con los de la citada tumba núm. 350 de La Osera (Quesada, 1989, II, 22-23 y 75). En la necrópolis de La Serreta conocemos dos discos lisos de bronce, uno de los cuales cubría los restos cremados de la tumba núm. 4, de $25 \mathrm{~cm}$ de diámetro, dotados de un reborde externo de hierro que en cuatro puntos conforma una abrazadera con anilla por donde pasarían las correas (Cortell et alii, 1992, fig. 15). 

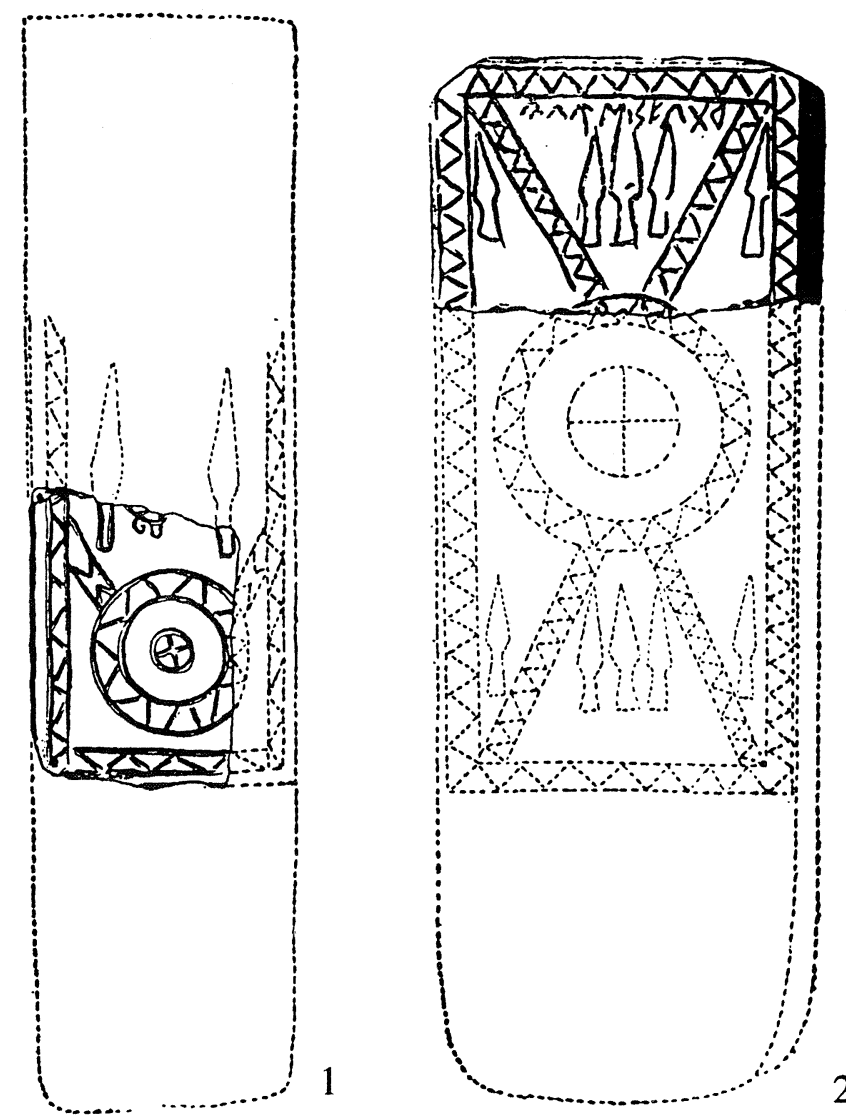

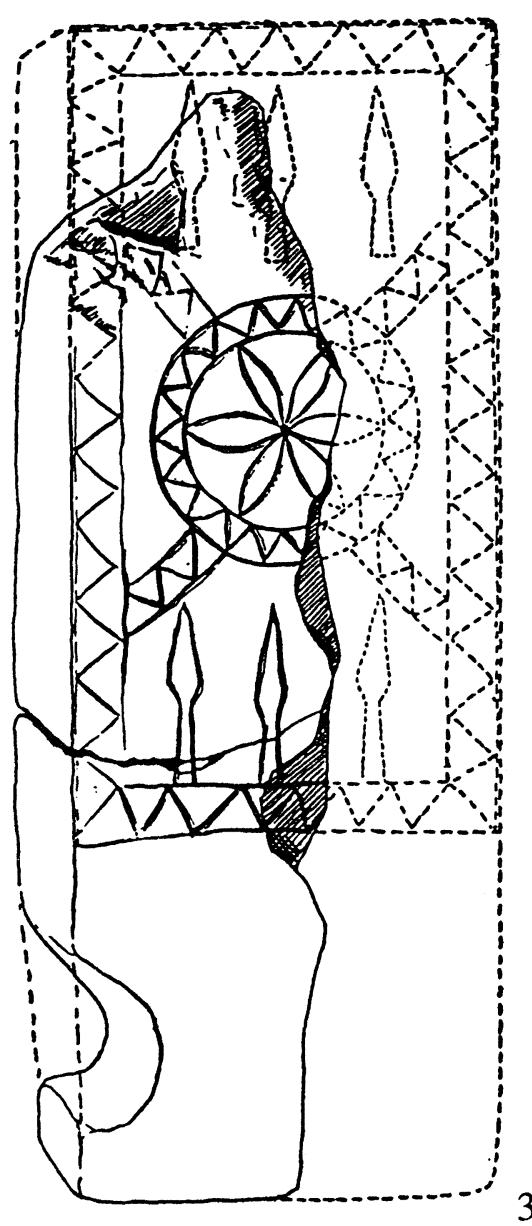

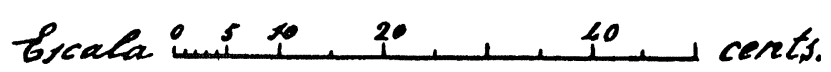

Fig. 8.-Estelas ibéricas de Cretas (Teruel), según Cabré, 1915-1920, figs. 439 a 442.

gueruela, 1990, 141-148), el busto de guerrero de La Alcudia (Albertini, 1935; Ramos Folqués, 1950, 359, fig. 1) y el del Parque Infantil de Tráfico (Ramos Fer-

También en los discos del Cabecico aparecen grupos de orificios dispuestos a intervalos en el borde con el mismo fin. El ejemplo de Altea la Vella, citado por Almarche $(1918,66)$ es más inseguro. Igualmente, en la monografía de la necrópolis del Cabezo Lucero no se reconoce ningún disco-coraza, aunque sí se han identificado escudos y grebas (Uroz en Aranegui, Jodin, Llobregat, Rouillard y Uroz, 1993, 124127). En Castellón se recogen dos referencias que no suscitan consenso entre los investigadores del tema. En distintas tumbas de la necrópolis de La Solivella -entre ellas la rica tumba núm. 14 y la núm. 27 - se documentan distintos discos decorados en bronce, con paralelos en otras piezas ibéricas y esculturas del $\mathrm{S}$ de Francia como la de Grézan, según Fletcher (1965, láms. VII, XXV). Estos discos han sido definidos con posterioridad, bien como posibles discos-coraza nández y Ramos Molina, 1992, 42, fig. 8, lám. XX), ambos de Elche (Alicante), el torso masculino de La Losa de Casas de Juan Núñez (Albacete; Giménez

(Kurtz, 1985, 19-20; Quesada, 1997, II, 575), bien como escudos y no armaduras corporales (Negueruela, 1990, 145). Por otro lado, en las tumbas núms. 9 y 10 de la necrópolis de El Puig de Benicarló se hallaron dos discos de bronce, uno de ellos de $17 \mathrm{~cm}$ de diámetro (Meseguer y Giner, 1983, figs. 21 y 24), probablemente pertenecientes a corazas, en opinión de Kurtz (1985, 20) o Quesada (1997, II, 575), o bien, como en el yacimiento anterior, a defensas de escudos según la hipótesis de Negueruela $(1990,146)$. Finalmente, en el área costera catalana contamos con las referencias de la tumba núm. 14 de La Oriola y la Granja Soley (Quesada, 1997, I, 575). A estos ejemplos, finalmente, se puede sumar el impreciso ejemplo en bronce de Cova Monja en Mallorca, presentado inicialmente por Cabré de Morán $(1949,188)$ y recogido con posterioridad por otros investigadores. 

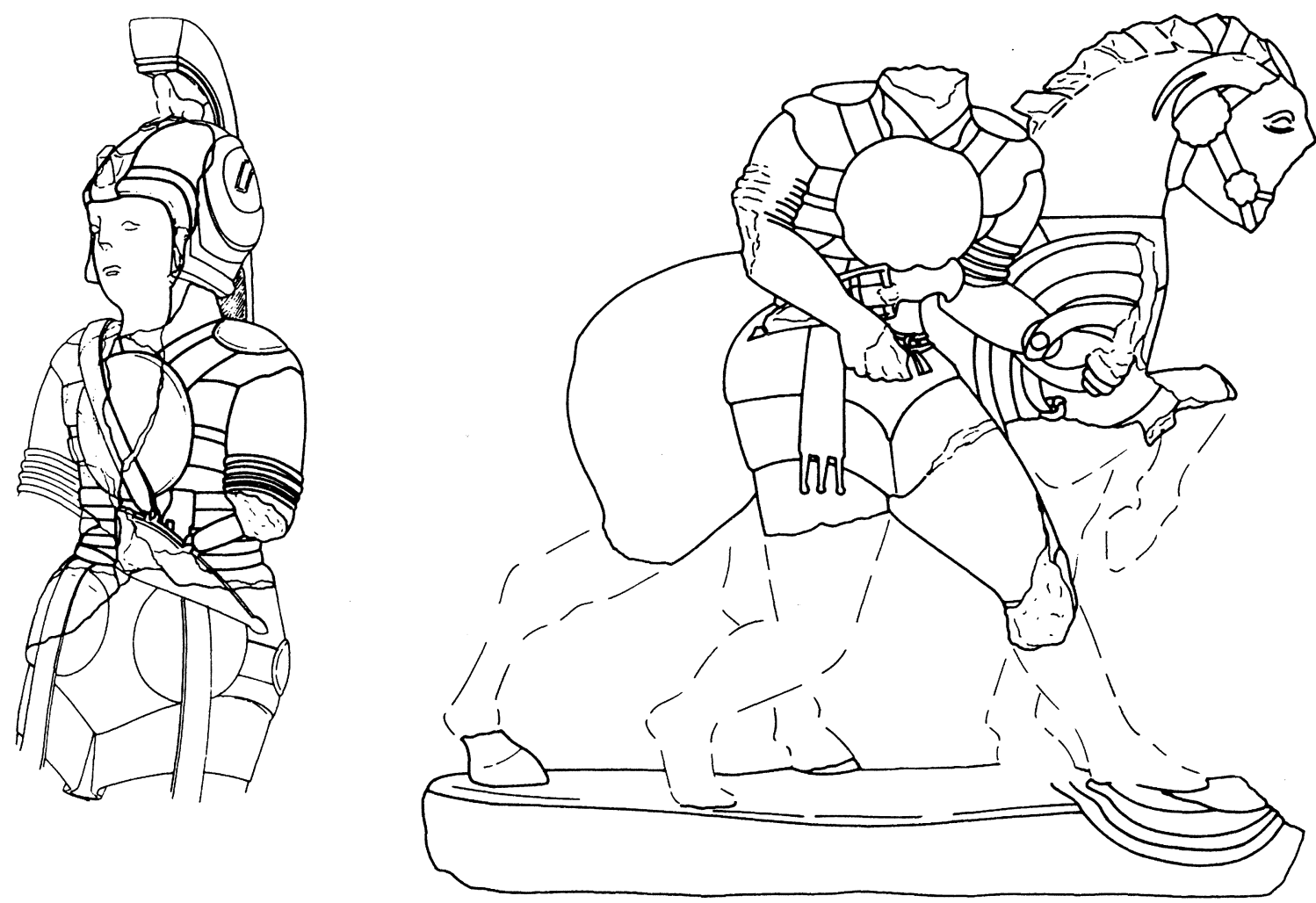

Fig. 9.-Esculturas de los “guerreros núms. 1 y 4” del Cerrillo Blanco de Porcuna (Jaén), según Negueruela, 1990, fig. 4 bis y 10.

Ortuño, 1988; Ruano, 1987, I, 431, AB-2) y el de La Torrecica-Llano de la Consolación de Montealegre del Castillo (Albacete; Ruano, 1987, I, 431, AB-399). El torso de guerrero a caballo del túmulo núm. 20 de la necrópolis de Los Villares (Albacete) presenta una indumentaria similar a la de los guerreros de Porcuna, con hombreras y correas de sujeción, aunque sin discos-coraza (Blánquez, 1993, 92).

Sin duda, las esculturas de Porcunà (fig. 9) $-\mathrm{y}$ singularmente el denominado guerrero núm. 1son las que mejor ilustran la morfología y disposición de estas armaduras (Negueruela, 1990, figs. 4, 4bis, etc.). Grandes discos lisos - en el pectoral del citado "guerrero núm. 1" con todo su perímetro biselado- de entre 21-23 cm de diámetro en los pectorales y de 23-27,5 cm en los espaldares y anchas correas, que seguramente serían de cuero y asegurarían la sujeción de los elementos, así como protecciones en los hombros conforman una estructura compleja, reproducida en otras esculturas de distintos territorios ibéricos. Así, la pieza acéfala de La Losa (fig. 10) muestra discos-coraza lisos de $25 \mathrm{~cm}$ de diámetro, sujetos por medio de correas - de unos $6 \mathrm{~cm}$ de anchura-. Desde el disco delantero pasan dos correas, una por encima del hombro izquierdo y otra por debajo de la axila izquierda; se cruzan por la espalda y salen por el hombro contrario pasando otra vez bajo el disco delantero para, finalmente, sujetarse en el cinturón. A modo de complemento de este sistema de correas (Giménez Ortuño, 1988, figs. 2 y 4) se ha propuesto la existencia de una pieza, tal vez de lana, para evitar el roce directo sobre la piel. Por su parte, la escultura de La Torrecica, muy mal conservada, representa la espalda de un torso masculino donde un pequeño disco-coraza permanece sujeto, de nuevo, por dos tirantes aspados sobre los hombros. Finalmente, en pleno territorio contestano, la magnífica pieza del busto de guerrero de La Alcudia, tantas veces citada, evidencia una gran minuciosidad descriptiva, reproduciendo los detalles del núcleo figurado con cabeza de lobo en la coraza pectoral. Por lo demás, el sistema de sujeción mediante correas - en este caso, ornamentadas con bellotas en relieve, posiblemente de cuero con apliques metálicos- que pasan por los hombros y bajo las axilas, es el mismo que ya hemos descrito en otras esculturas, apreciándose en este caso un nudo de cintas que podría representar el sistema de cierre de la armadura. La escultura hallada en el Parque de Elche, muy fragmentada, 


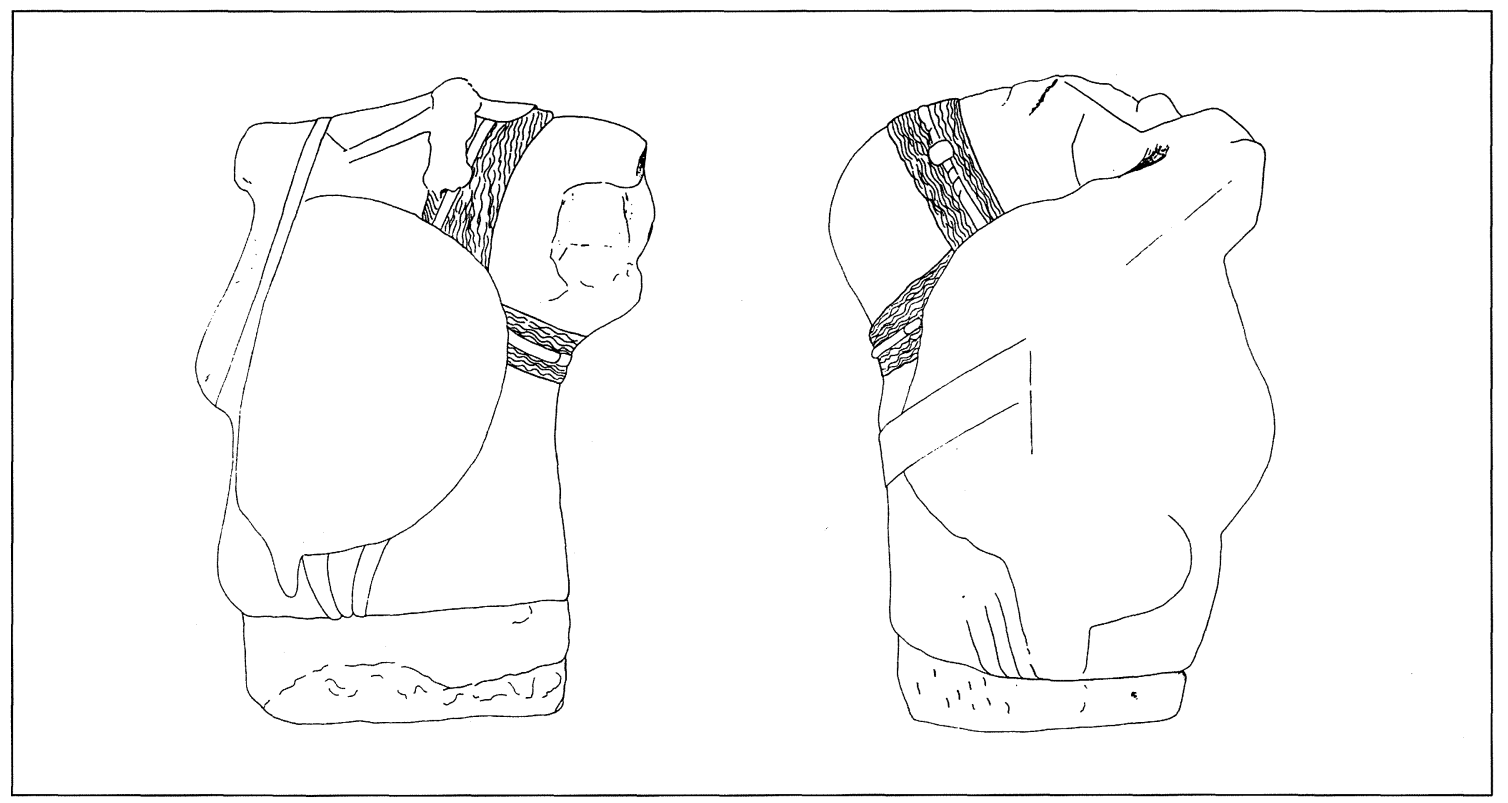

Fig. 10.-Escultura del guerrero de La Losa de Casas de Juan Núñez (Albacete), según Giménez Ortuño, 1988, figs. 1.I y II.

muestra la protección de hombros y el sistema de correas cruzadas por la espalda. Interesa destacar la presencia de parte de un orificio circular de $11 \mathrm{~cm}$ de diámetro en la escultura, que se halla totalmente vaciada en su interior, lo que ha permitido definirla como estatua-urna, dentro de una serie conocida en el mundo ibérico (Olmos y Chapa, 1997, 168).

En síntesis, las representaciones de discos-coraza en la estatuaria ibérica pueden ser lisas —en su mayor parte y el ejemplo que estudiamos no parece una excepción- o decoradas, como en el caso de La Alcudia de Elche, con cabeza de animal, dotado de una fuerte carga simbólica, presente en el relieve de Minerva de la muralla de Tarraco, del siglo II a.C., donde aparece también una cabeza de lobo en el escudo de la diosa, a modo de gorgoneion (Grünhagen, 1976). Igualmente uno de los guerreros de Osuna muestra en el umbo de su escudo una cabeza de lobo (Rouillard, 1997, núm. 12). La imagen terrorífica del lobo, protectora y a la vez amenazante, unida a la representación del guerrero en el caso ilicitano, proyecta un valor apotropaico y probablemente ritual e iniciático, que ha sido analizado en profundidad y resaltado por distintos autores, a los que nos remitimos (Negueruela, 1990, 148; Almagro, 1997; Olmos, 1997, 96, entre otros). En los bronces votivos masculinos armados no se han identificado discos-cora$\mathrm{za}$, aunque sí que se ha reconocido el sistema de almohadillado o de protección para los hombros que documentan las esculturas de Porcuna o Elche (Nicolini, 1969, 159).
En cuanto a la consideración del origen de este elemento, existe prácticamente un consenso en cuanto a su procedencia incuestionablemente itálica ${ }^{12}$. Las diferencias de los discos-coraza itálicos y los ibéricos son muy evidentes en lo que se refiere a la cronología — aquellos son mucho más antiguos-, el sistema de suspensión, la ausencia de protecciones sobre los hombros o las dimensiones (Negueruela, 1990, 152). Los cardiophylakes o guardacuori itálicos aparecen a principios del siglo vil y dejan de utilizarse en el siglo v a.C., según ha visto Kurtz (1991, 188, n.p.p. 3). A modo de ejemplo, ya señalado por Blázquez y Navarrete $(1985,63)$ a propósito de los guerreros de Porcuna, podríamos citar la conocida escultura del guerrero de Capestrano (L'Aquila, El Piceno) del siglo vi a.C., la más importante hallada en Italia central (Bianchi Bandinelli y Giuliano, 1974, 104, figs. 117 y 118). Se trata de la estatua de un guerrero que coronaba una tumba. En su mano derecha porta una probable insignia de mando; también va armado con espada y puñal, además de un espléndido disco-coraza circular. Es interesante hacer notar que la escultura se acompaña de una inscripción que en opinión de Bianchi Bandinelli y Giuliano indicaría quién era el difunto y el equiva-

${ }_{12}$ Para la cuestión de las semejanzas entre testimonios de regiones alejadas entre sí, $c f$. Kimmig, W. (1983): Die griechische Kolonisation im westlichen Mittelmeergebiet und ihre Wirkung auf die Landschaften des Westlichen Mitteleuropa, Jahrbuch des Römisch-Germanischen Zentralmuseums, Mainz, 30, 5-78, lám. 22-5 y 65-7. 
lente de su cursus honorum. Esta pieza ha sido comparada con la cabeza hallada en Numana (ibidem, fig. 108) y, especialmente, la estela de Guardiagrele (ibidem, fig. 119; nuestra fig. 11), también con disco-coraza y, en este último ejemplo, con correas decoradas, ambas del siglo vi a.C.

Por otro lado, la asociación del guerrero armado, protegido por coraza, y la estela funeraria tiene un ejemplo muy ilustrativo en la serie de estelas daunias, recientemente reestudiada desde el punto de vista de su iconografía y morfología (Salomone, en Pontrandolfo, Mugione y Salomone, 1997, 297 318). Destacaremos aquí el grupo de estelas con armas, cuya panoplia básica se compone de cardiophylax, escudo y espada, según Nava (1980 y 1984). El cardiophylax de la cara anterior es generalmente, en estos ejemplos, de forma rectangular con extremos alargados, levemente cóncavos (Pontrandolfo, Mugione y Salomone, 1997, figs. 17, 20, 22 y 26) y a veces se decora con motivos geométricos en su interior. La práctica totalidad de las piezas carece de contexto arqueológico a excepción de los casos en que las estelas son reutilizadas en tumbas o estructuras de hábitat, siempre del siglo vi a.C. (ibidem, 298, n.p.p. 49). Como evidencia arqueológica, también en el territorio itálico, destaca el tantas veces citado ajuar de la tumba núm. 388 de la necrópolis de Alfadena, en el que se localizaron las piezas in situ de una panoplia, donde el disco-coraza cuelga del hombro derecho (Negueruela, 1990, 151, fig. 22). También, fuera de este ámbito, en la tumba de cámara núm. 90 de Aleria fueron hallados dos discos-coraza de bronce de $17,5 \mathrm{~cm}$ de diámetro (Jehasse y Jehasse, 1965, 455).

No podemos, finalmente, dejar de mencionar la pieza antes citada de Grézan (Gard; v. n.p.p. 11), con figuración de cinturón y coraza pectoral ornamentada, en este caso de forma rectangular, definida inicialmente por Déchelette (1927, 1041, fig. $705)$ y luego por Jacobsthal $(1969, \mathrm{I}, 6)$ como escultura de guerrero céltica del $\mathrm{S}$ de Francia -en ocasiones aparece denominada como celtibérica por el estilo de la escultura y las características del cinturón-. Sin embargo, a pesar de este caso, es más evidente el paralelismo de las piezas ibéricas -entre las que se encuentra la que aquí presentamos-, con las itálicas, de las que hemos comentado tan sólo algunos ejemplos bien conocidos.

En general, en cuanto a la cronología, los discoscoraza metálicos encontrados en los ajuares de las necrópolis peninsulares no parecen bajar de mediados del siglo IV a.C. La mayoría ha sido inscrita dentro del siglo v a.C., asociados a la fase antigua de la panoplia ibérica. Por lo que respecta a las re-

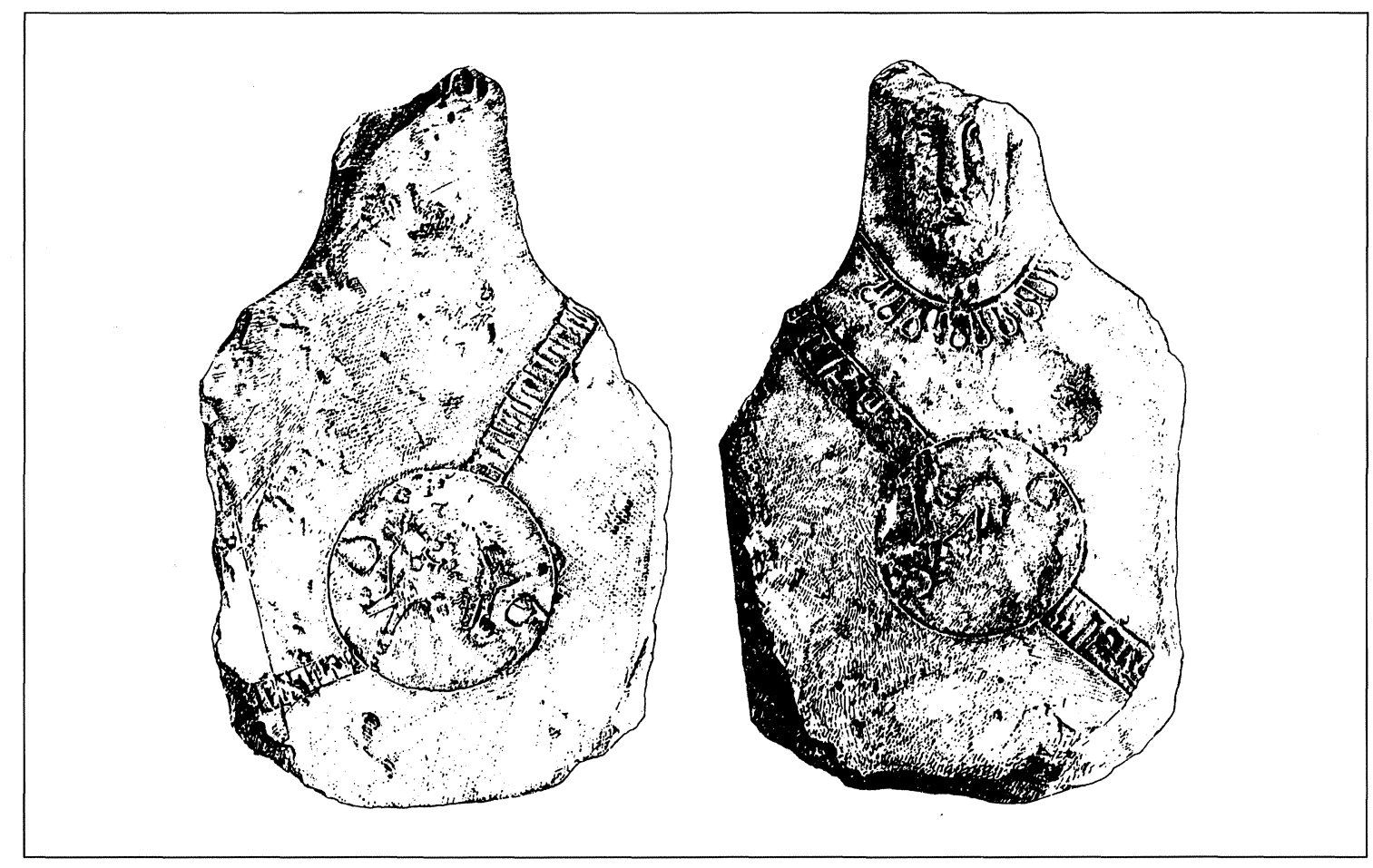

Fig. 11.-Estela de Guardiagrele (Chieti, El Piceno, Italia), según Negueruela, 1990, fig. 22. 
presentaciones en piedra, la datación de la escultura de La Losa, por ejemplo, se ha relacionado con la atribuida al caballo procedente del mismo yacimiento, así como con la de los conjuntos de Porcuna y La Alcudia de Elche, enmarcándose, por tanto, a mediados del siglo v a.C. (Giménez Ortuño, 1988, 132). La escultura del jinete o caballero de Los Villares se fecha en el 410 a.C., según Blánquez $(1993,91)$ a partir del análisis del ajuar del túmulo núm. 20. En síntesis, como ha observado Quesada, apenas hay armas defensivas del periodo en que mejor conocemos otras armas ofensivas como la falcata, la lanza o el soliferreum, es decir siglos IV y III a.C. Será a partir de finales del siglo III y sobre todo los siglos II y I a.C. cuando volvamos a encontrar evidencias sobre armamento defensivo pasivo: las cerámicas con decoración figurada y los textos clásicos así lo demuestran (Quesada, 1997, II, 583). Precisamente en este último momento -ibérico tardío o final- se enmarca la estela de Nogueruelas con inscripción que aquí estudiamos.

\subsection{La inscripción ibérica}

El campo epigráfico mide $30 \times 15,5 \mathrm{~cm}$ y no presenta ningún tipo de marco o delimitación. El texto aparece distribuido en cinco renglones, siguiendo otras tantas líneas de guía para el trazado de los signos. La altura de los renglones es la siguiente: 1) 2,3-2,7; 2) 2,7-3; 3) 3,6-4; 4) 3,5-3,7 cm. En su extremo derecho, la primera línea de guía aparece duplicada, lo que puede explicarse como una equivocación. El último renglón no cuenta con línea de guía por la parte inferior. El lapicida debió trazar inicialmente cinco líneas de guía para cuatro renglones con la idea de que el texto no ocuparía un espacio mayor, pero se quedó corto en su cálculo y necesitó añadir un sexto renglón para el que sin embargo no trazó la correspondiente línea de guía por su lado inferior. De esta manera, las cinco primeras líneas ocupan casi todo el ancho de la estela y tienen una longitud parecida, pero la sexta cuenta sólo con dos signos. A partir del segundo renglón los signos descansan en la línea de guía inferior y no alcanzan la superior. Su altura es la siguiente: 1) $1,7-3,2$; 2) $1,9-2,5$; 3) 1,42,4 ; 4) $1,7-3,4$; 5) 2-2,4 cm.

En cuanto a la ordinatio, el texto parece estar bien alineado a la izquierda. Los signos iniciales de las tres primeras líneas están situados aproximadamente en la misma vertical; en la cuarta es imposible precisarlo por la presencia de un desconchado, aunque posiblemente su inicio se desplazó un poco a la derecha a causa del estrechamiento de la estela que reduce la anchura del campo epigráfico, por lo que el signo inicial debió estar situado a la altura del primero de la quinta, donde este desplazamiento es evidente. El final de las líneas en el margen derecho es irregular, pues la primera y sobre todo la quinta son más cortas que el resto. La parte central del texto, formada por las líneas 2-4, ocupa toda la anchura del campo, en particular la tercera que es la más larga. En algo más de la mitad izquierda de las líneas 2-3 los signos están más espaciados, mientras que en la derecha están más próximos.

\subsubsection{Comentario paleográfico}

El texto no presenta signos de interpunción. El trazado de los grafemas no muestra una gran pericia, según se demuestra en algunas correcciones en la incisión de los trazos, el trazado asimétrico de algunos signos y algunos ángulos no cerrados en éstos; parece inseguro, incluso vacilante en algunos casos. El surco es estrecho y poco profundo. La altura no es uniforme, puesto que algunos signos se prolongan más allá de la línea de guía, como es el caso de la $\bar{m}$ del primer renglón que alcanza $3,2 \mathrm{~cm}$ y sobresale $7 \mathrm{~mm}$ por encima de aquélla. Algunos signos presentan particularidades en el ductus: en la primera línea el triángulo de la $r$ no se cierra completamente en su vértice inferior, el trazo vertical de $b a$ aparece curvado ligeramente hacia la derecha y la $i$ final tiene el trazo vertical ligeramente quebrado, lo que debe corresponder a una corrección del lapicida; en la tercera los tres trazos de to no llegan a unirse en su extremo inferior, el trazo vertical de ba está inclinado a la derecha y el antepenúltimo signo, posiblemente una $n$, prolonga excesivamente su trazo principal por la parte superior.

El signario utilizado es el ibérico nororiental. Las formas de los signos son las habituales en éste. En total han sido identificados con seguridad 15 signos. Su adscripción a la clasificación numeral de Untermann (MLH III, 1, 246-247) es la siguiente: $s$ 2 ; e 1 ; $l 1$; ta 1 ; r 1 ; ba $1 ; n 1 ; \bar{m} 3$; $i$; be 1 ; r 3 ; $u$ 3 ; to $2 ; s 2$; o 2 . La forma que adopta el signo $\bar{m}$ cuenta con paralelos relativamente cercanos en las estelas de Benassal y Canet lo Roig II (E.9.1 y F.2.2). Con respecto a las recientes propuestas de datación paleográfica de Rodríguez Ramos (1997), que se basan fundamentalmente en la evolución del signo be, éste aparece con una de las formas modernas (be-6), una de las más frecuentes, que se asocia a leyendas monetales, estelas funerarias y cerámica campaniense B y puede datarse en el periodo 150 50 a.C. El signo $o$ figura con la forma clásica $(o-1)$, 
de amplia cronología. El signo $l$ aparece con la forma moderna $l-2$, con una datación de 225-50 a.C. El signo $\dot{r}$ presenta la forma $r$ - 3 , en la que se recogen variantes evolutivamente intermedias que el autor no considera antiguas. El signo $s$ adopta una forma moderna $(s-1)$, en la que posiblemente se aprecia el influjo latino, que fecha en 275?/250-50 a.C. El signo $\bar{m}$ presenta una forma no recogida por el autor, aunque cabe considerarla una variante de $\bar{m}-1 \mathrm{a}$, con una amplia cronología (400-50 a.C.). La forma del signo $b a$ es la más moderna ( $b a-2)$, con una datación de 300/275-50 a.C. Finalmente, el signo to adopta la forma inusual to-2, que supone una evolución de $t i-3$ y puede fecharse hacia 200-50 a.C.

En resumen, el signario presente en el texto de la estela de Nogueruelas adopta en su mayor parte formas modernas, propias del periodo iberorromano, que pueden fecharse entre finales del siglo iII/ principios del II y mediados del I a.C., y de manera más concreta, formas propias de los esgrafiados que aparecen mayoritariamente sobre cerámica campaniense B y se fechan entre 150 y 50 a.C. Ésta es la cronología que Rodríguez Ramos atribuye en su periodización a la fase Iberorromano 2 o Neoibérico 4 (150/135-50 a.C.), caracterizada, entre otros rasgos, por la aparición de las formas be-6 y to-2.

\subsubsection{Transcripción y comentario epigráfico}

El estado de conservación del texto es desigual. La primera línea puede leerse completamente, pero los signos conservados en el lado izquierdo de la segunda a la cuarta están en parte dañados o no se conservan; de la misma manera, algunos signos del resto de estas líneas, sobre todo de la cuarta, son dudosos. La lectura que proponemos es la siguiente:

\section{seltarban̄̄ $i$ \\ baș[.]berunen $<\bar{m}>i$ \\ bastobaśoren̄ $\bar{m} i$ \\ [.]babe[.]berbe[.] \\ $\bar{m} i$}

El carácter incompleto de la lectura realizada, con algunas dudas en las líneas 2 a 4, impide identificar todos los elementos significativos contenidos en el texto. Pasamos ahora a describir el texto línea a línea, con los problemas de lectura, dudas y propuestas que hemos realizado después de una escrupulosa autopsia.

Línea 1: la forman 9 signos. Resulta clara la lectura del lexema seltar. A continuación sigue un trazo vertical levemente curvado hacia la derecha que puede identificarse con $b a$, y otro inclinado en la misma dirección que arranca desde la línea de guía inferior y parece corresponder a $n$, tras el cual puede leerse con claridad el sufijo $-\bar{m} i$. Esta lectura ya fue señalada por Ventura, que recordando su presencia en la estela de Sinarcas, apunta que el elemento ban que en aquélla aparece entre ambos no puede reconocerse con seguridad en ésta. Sin embargo, la separación de los dos elementos cuya lección es segura y la presencia de los dos grafemas mencionados enmedio, aunque incompleto el segundo, hacen bastante segura esta lectura.

Línea 2: debió estar constituida por 10 signos, que están bastante espaciados excepto los 7-9. El primero, $b a$, es seguro. Sigue un espacio bastante dañado en el que debían figurar dos signos, de los que puede verse el extremo superior del primero, un pequeño trazo inclinado a la derecha que podría corresponder a varios signos: $s, r, b e$ e incluso $u$; del segundo no queda ni rastro. A continuación, los siete signos identificados pueden leerse con bastante seguridad de la siguiente manera: beŕuneni.

Linea 3: la transcripción es muy problemática por su desigual estado de conservación. Parece estar formada por 11 signos, que están bastante espaciados en más de la mitad izquierda de la línea y bastante juntos en el resto. Del primer signo queda un trazo vertical, que parece corresponder a $b a$. Del segundo quedan dos pequeños trazos formando un ángulo abierto a la derecha que deben corresponder a la mitad superior de una $s$. El tercero es con seguridad to. Según las propuestas anteriores nos encontramos con el elemento bisilábico basto. El siguiente es un trazo recto ligeramente inclinado hacia la derecha, que parece $b a$, aunque no puede descartarse que sea parte de una $n$. Siguen tres trazos que parecen corresponder a una $\mathrm{M}$ bastante abierta, por lo que se trata de una $s$. A continuación encontramos dos trazos verticales paralelos con otro diagonal enmedio, que debe corresponder a una $o$. El siguiente signo es $r$, cuyos ángulos no llegan a cerrar. Tenemos así un segundo elemento bisilábico: baśor. A continuación figura un trazo vertical de cuya mitad arranca otro corto inclinado hacia la derecha, que debe corresponder a $e$. Sigue un espacio con un amplio desconchado en el que pudo figurar algún signo, aunque tal vez sea antiguo y no fue aprovechado para la incisión. A continuación se aprecia lo que podría ser la parte superior de una $n$, en cuyo trazado no puede descartarse algún error. En el final de la línea puede leerse con claridad el sufijo $-\bar{m} i$, sin que figure ningún otro signo a continuación.

Línea 4: las dificultades de lectura de esta línea son todavía mayores. Se distinguen con seguridad 8 signos, que parecen estar bastante espaciados, aun- 
que no puede descartarse que hubiese algún otro. El principio presenta una zona erosionada en la que puede distinguirse en la parte inferior, a la altura del segundo signo de la línea anterior, un pequeño trazo quebrado inclinado hacia la derecha. Sigue un trazo vertical que podría corresponder a $b a$, aunque no puede descartarse que sea $u$. A continuación hay un largo espacio dañado en el que no puede identificarse más que los extremos inferiores de algunos signos. Del primero queda una pequeña $\mathrm{v}$ invertida en la parte inferior que corresponde a be. Del siguiente tan sólo queda el extremo de un trazo vertical. Sigue un aspa que podría corresponder de nuevo a be y un espacio vacío en el que pudo haber otro signo. A continuación se distingue una $r$ de la que falta la parte inferior. El final está constituido por el signo be, identificado con bastante seguridad, seguido de un trazo vertical del que arrancan otros dos cortos que puede corresponder a $e$.

Línea 5: la ocupan dos signos y debe comenzar a la altura del primero de la anterior. El primero es con seguridad $\bar{m}$ y el segundo es una $i$ con el brazo bastante largo; se trata de nuevo, por tanto, del sufijo $-\bar{m} i$.

\subsubsection{Análisis y comentario lingüístico}

Aunque la desigual conservación del texto impide su estudio completo y la inexistencia de interpunciones no facilita la delimitación de las "palabras", es posible identificar algunos elementos -en parte ya conocidos- que pueden ser analizados individualmente. Pasamos, pues, a desarrollar el comentario lingüístico del texto.

\section{seltarban $\bar{m} i$}

El término seltar/siltar, con oscilación vocálica e/i (MLH III, 1, § 501, Velaza, 476; Quintanilla, 1993, 733), aparece exclusivamente en inscripciones sepulcrales y nunca en otros soportes; suele figurar en último lugar en los textos funerarios breves y, siempre, después de los antropónimos. Así sucede en las inscripciones de Caspe (E.13.1), Cretas (D.10.1), Cabanes (F.5.1) y Sinarcas (F.14.1). Por ejemplo, en la estela de Cabanes el texto es iltiŕbikis.en.seltar. $\bar{m} i$, esto es, una cadena formada por nombre personal (NP) + sufijo + seltar + sufijo. El caso que analizamos es, por tanto, el primer texto funerario en el que este elemento figura en primer lugar, antepuesto al nombre personal del difunto.

Las hipótesis de interpretación sobre este elemento son muy variadas. Para Gómez-Moreno $(1949,278)$ tiene la apariencia de complemento per- sonal. Beltrán Martínez $(1953,500)$ lo explica a partir del vasco seldor ("haz o pila de leña para hacer carbón"), de donde vendría "pira" y, por extensión, "tumba", hipótesis admitida por Tovar (1959, 47; $1961,58 ; 1979,482-483)$. A este respecto, Michelena $(1961,22 ; 1976,354-358)$ señala las dificultades contenidas en la misma lengua vasca para esta interpretación. Para de Hoz (1983, 366, 385, 387-388) es un nombre común relativo a la tumba o el enterramiento, un término perteneciente al léxico especializado ibérico. Untermann (1984b, 113; 1990, MLH III, $1, \S 586)$ propone relacionarlo con el concepto de sepultura. Siles $(1985,294)$ señala que su interpretación como nombre personal no es imposible, si se tienen en cuenta los abundantes temas en - ar que recoge Michelena (1961, 9). Para Silgo (1994, 232), por el contexto puede deducirse que su significado es "tumba". Recientemente, Velaza (1996a, 55) reconoce que esta equivalencia resulta atractiva, pero recuerda que en los paralelos romanos de la misma época no se acostumbra a mencionar la tumba.

La partícula ban aparece también sobre cerámica, pesos y monedas y — como ha señalado Untermann - frecuentemente va en posición anterior, en algunos casos posterior y sólo ocasionalmente medial (MLH III, 1, § 514). Cabe recordar que en la estela de Sinarcas aparece por dos veces la secuencia seltarban. $\bar{m} i$. en posición posterior a sendos nombres personales (Fletcher, 1985, 18). Sobre su interpretación hay distintas hipótesis ( $c f$. Siles, 1985, 96-97; Silgo, 1994, 61-64), pero ninguna cuenta con una aceptación mayoritaria. Para Gómez Moreno (1949, 279-280) es "indicio de referencias personales”. Beltrán Martínez (1953, 500-501) lo explica por el vasco bat ("uno"), hipótesis rechazada por Tovar (1951, 294), quien considera que debe ser un "signo pronominal para posesivos" (Tovar, 1979, 482-483). Michelena (1976, 357) le atribuye un valor de determinante. Para de $\operatorname{Hoz}(1983,368)$ se trata de un sufijo nominal o un elemento pronominal. Por su parte, Velaza (1991, 44-45) opina que probablemente debe tratarse de varios homógrafos con valor léxico diferente.

Le sigue el sufijo $-\bar{m} i$, sobre el cual cabe recordar que el signo $\mathrm{Y}$ ha sido objeto de diversas interpretaciones ( $c f$. Fletcher, 1979; Siles, 1981; Untermann, 1984a; Valeri, 1993; Velaza, 1996a, 41). La mayor parte de los autores le dan un valor nasal y lo transcriben como $\bar{m}$, pero Fletcher y Silgo $(1994,259)$ lo hacen como $w$. Este sufijo aparece pospuesto a nombres personales, tanto en estelas funerarias como en letreros escritos sobre vasos. La mayoría de los investigadores coinciden en atribuirle una función pronominal. Gómez-Moreno $(1949,280)$ señala su po- 
sible relación con el vasco ni ("yo"), con lo que tendría un sentido personal o posesivo. Beltrán Martínez $(1953,500)$ lo relaciona con el vasco $i$ ("tu"). Tovar $(1959,49 ; 1960,23)$ indica que podría tratarse de un pronombre de primera persona ("yo"), interpretación que recoge Michelena $(1961,19 ; 1976$, 356-358). Untermann (1972, 467; MLH III, 1, § 534) la considera partícula posesiva, pero señala que puede interpretarse como morfema casual, forma finita de verbo substantivo, morfema deíctico o pronombre de tercera o primera persona. Siles (1980, $186-187 ; 1985,266)$ lo interpreta como un pronombre personal de primera persona, pero sin descartar la posibilidad de que se trate de un verbo o una partícula que expresa la idea de posesión. Finalmente, Velaza $(1991,103)$ señala que su valor es posiblemente posesivo o genitivo. La presencia en primer lugar de esta expresión y los sufijos que la acompañan se correspondería - según la interpretación más común- con un comienzo del tipo "sepultura de", pero resulta extraña y anómala la anteposición de este término al nombre del difunto que en la mayoría de los textos complejos ocupa el primer lugar.

\section{baș[.]berúnen $<\bar{m}>i$.}

Hemos visto como el primer signo de la primera línea puede ir seguido de otro cuya identificación es insegura: $s, r$, be e incluso $u$. De entre estas posibilidades, el radical bas- es bien conocido y no presenta mayores problemas de identificación (Siles, 357-386; Velaza, 134-147; Silgo, 1994, 68-71). Untermann (MLH III, 1, § 515) señala su presencia en antropónimos. Lo mismo sucede con bar-, aunque no es tan frecuente (Siles, 344-356; MLH III, 1, § 566; Velaza, 125-133; Silgo, 1994, 66-68). La secuencia babe figura en un contrapeso de Azaila (Siles, 236). Por último bau está documentado sobre cerámica campaniense en Ensérune (Siles, 387). De estas posibilidades, la que más frecuentemente encontramos en los textos es la primera. Esta secuencia inicial debió completarse con un tercer signo del que nada se conserva. Pudo tratarse de $i$, que permitiría la restitución del primer elemento de un NP como basi (MLH III, 1, 214), que encontramos en la estela de Sinarcas (basibalkar: F.14.1; Siles, 381), Ullastret (basiaŕebe[---: Siles, 380) y Alcoy (basibes: Siles, 382; basiŕtiŕ: Siles, 383). Sin embargo, no puede descartarse la presencia de to, anticipando el mismo primer elemento del NP que figura en la tercera línea (basto-), que comentaremos más adelante.

Los siete signos identificados a continuación pueden leerse con bastante seguridad como beru$n e n i$. En primer lugar encontramos un radical beŕbien documentado que aparece como marca de pro- piedad en diversas piezas cerámicas ( $c f$. Palamós: C.4.2; Sosés: D.11.3; Azaila: E.1.370-371); formando parte del elemento berí figura en una fusayola de Palamós (C.4.2), en una estela de Sagunto (berian: F.11.10), en el plomo de Castellón de la Plana (berikaŕsense: F.6.1; Siles, 428) y en una inscripción rupestre de Roda de Ter (berikaŕs: D.3.1; Velaza, 165); también lo encontramos en un vaso de Liria (beréi: F.13.6) y en una inscripción monetal (beŕsa: MLH I A.30; Siles, 429). Entre los antropónimos es el primer elemento de beŕbeinari en la estela de Sinarcas (F.14.1; Siles, 427). El radical un- es conocido, aunque no frecuente ( $c f$. Siles, 1425-1435; Velaza, 550-552). Sin embargo, la forma berun no está documentada, por lo que cabe pensar que nos encontramos ante una variante de beŕon (MLH III, 1, 217), con cambio vocálico o/u (MLH III § 501), componente onomástico documentado en Castellón de la Plana (boŕberon: F.6.1; Siles, 532), Mogente (bo(r)beron y kaniberon: G.7.2) y Abengibre (aiberon: G.16.2). Nos encontramos, pues, con un primer NP compuesto de dos elementos bisilábicos: bas[.]beŕun, con las dos posibilidades antes apuntadas para la restitución del signo borrado ( $i /$ to $)$.

A continuación figura el sufijo -en y un final en $-i$ que debe corresponder en realidad al sufijo $-\bar{m} i$, con omisión de la nasal, lo que podría explicarse como un error del lapicida. Posiblemente nos encontramos ante el complejo sufijal -en. $\bar{m} i$. La partícula -en parece expresar la idea de posesión, por lo que se considera un sufijo de genitivo ( $c f$. Tovar, 1949, 90-95; Tovar, 1959, 45-46; Tovar, 1960, 20; Tovar, 1961, 62-64; Michelena, 1961, 15-18; Michelena, 1976; Michelena, 1979, 34; de Hoz, 1983, 388; Siles, 887; MLH III, 1, § 521; Velaza, 1991, 67-68; Silgo, 1994, 162-163). Es relativamente frecuente y aparece en posición final acompañando a antropónimos, como en la estela de Cabanes (iltiŕbikisen: F.5.1; Siles, 1016) y Ensérune (ibesoren: B.1.25; Siles, 971), y también tras otras palabras y tal vez en forma reducida tras algunos topónimos. Tal y como posiblemente debe ocurrir aquí, en ocasiones va seguido del sufijo $-\bar{m} i$. Así lo encontramos, entre los más cercanos, en el texto incompleto de Algimia de Almonacid (---Jren̄̄ $i$ : F.24.1; Velaza, 757) y en Oliete (binkisauŕenm[i]: E.5.3; Siles, 468), y en otros como Ensérune (anaiośaren⿳亠丷⿵冂⿱八口𧘇: B.1.37; Siles, 140). En cuanto al sufijo $-\bar{m} i$, ya hemos hablado de él en la línea anterior.

\section{baṣtobaśoreṇ̄mi}

El elemento antroponímico basto es bien conocido (MLH III, 1, 215), y lo encontramos en la lápida de Les Coves de Vinromà (bastokitaŕ: F.4.1), en 
la inscripción monetal de una imitación de dracma ampuritana (bastokiśa: A.6.12; Siles, 376) y en un NP femenino sobre epígrafe latino de Terrassa (Bastogaunin: CIL II 6144). Le sigue el elemento baśor, que junto al anterior puede interpretarse como el NP bastobaśor. El elemento baśor debe ser una variante de baśur, con cambio vocálico o/u (MLH III, 1, $\S 501$ ), que se intrepreta como un radical bas- sufijado ( $c f$. Velaza, 142). Aparece en Yátova (F.20.3) y se relaciona con basiŕ (MLH III, $1, \S 564)$, también documentado en el mismo lugar (F.20.1; Velaza, 143-145). Hasta ahora no ha sido identificado como elemento antroponímico.

A continuación encontramos el sufijo -en, con los dos signos anómalamente distanciados y con dudas de lectura, aunque por tratarse de un morfo conocido parece razonable pensar que no falte ningún signo en medio de ambos. El final de la línea no ofrece ninguna duda en su lectura y reproduce de nuevo el sufijo $-\bar{m} i$. La lectura completa de la línea nos proporcionaría un NP, con la estructura tetrasilábica más habitual, seguido del mismo complejo sufijal que hemos restituido en la línea anterior: bastobaśoren. $\bar{m} i$.

\section{[.]ḅabe[.]berbe[.] $\bar{m} i$}

La intepretación de la cuarta línea resulta todavía más problemática por su deficiente estado de conservación. La presencia del sufijo $-\bar{m} i$ al final de la anterior permite suponer que en ésta empieza un nuevo elemento del texto. De la misma forma, la repetición de este sufijo en la quinta línea permite incorporarlo a este último elemento. Según las posibilidades de lectura anteriormente apuntadas, la secuencia babe, aunque infrecuente, no es deconocida (Azaila: E.1.361; Siles, 236), como tampoco lo es ube- (Cogull: Siles, 1404). A continuación de un signo irreconocible, sigue la secuencia berbe, seguida de otro signo de lectura insegura que podría ser $e$. Este posible encuentro entre dos vocales del mismo timbre no sería extraño, aunque su presencia en este caso sería atípica por dos razones: en primer lugar porque ambas parecen corresponder a la terminación del mismo elemento, y en segundo lugar porque - contrariamente a lo que es normal - no se ha producido una asimilación ni aparece algún elemento eufónico. En el final del texto, en la quinta línea, aparece de nuevo el sufijo $-\bar{m} i$, ya visto en las tres primeras.

\subsubsection{La estructura del texto}

Hasta ahora nos hemos limitado a identificar algunos elementos del texto, como el que lo encabeza y los dos antropónimos. Aunque su estado de conservación no facilita un análisis como el que hemos intentado, tanto la extensión del texto como la identificación y posición de algunos de los elementos señalados permiten abordar, aunque de manera somera, su estructura formular, buscando relaciones con otros textos de características similares.

Como han señalado varios autores (Untermann, 1984b, 111-115; MLH III, 192-194; Siles, 1986, 4042; Velaza, 1996b), la información proporcionada por los textos funerarios ibéricos no debe ser muy diferente de la que se encuentra en los latinos. En este sentido, de Hoz (1983, 384-388), Siles (1986, 40-42, nota 87) y Untermann (1987; MLH III, § 582-587) han elaborado varias clasificaciones de los diferentes formularios de las inscripciones funerarias ibéricas. En este tipo de textos el proceso de latinización habría introducido progresivamente el estilo formular romano. Así pues, los formularios contenidos en los textos ibéricos y latinos deben ser, en esquema, bastante parecidos (nombre, filiación, dedicante, edad, etc); por la misma razón, los textos ibéricos pueden aparecer incompletos, como en ocasiones sucede con los latinos, lo que explicaría la falta de regularización.

La presencia de antropónimos acompañados de otros términos, de determinados sufijos o de marcas, fundamenta esta interpretación. Tres de estos elementos y sufijos, para cuya comprensión se han buscado paralelos en los formularios sepulcrales latinos, se asocian al contenido funerario: aretake y variantes, eban y variantes y seltar. En esta línea, Velaza (1993, 161-165) ha propuesto para la inscripción de Civit (Tarragona) una estructura formular típicamente romana formada por el nombre del difunto, la filiación, la edad, el parentesco y el nombre de la dedicante. Por otra parte, la existencia de textos posiblemente bilingües para los que se han propuesto correspondencias semánticas entre términos ibéricos y latinos (aŕeteki = heic situs est; teba$n e n=$ coerauit , estos últimos con grafías arcaicas, aproxima cronológicamente ambas formas de expresión escrita. Posteriormente, Velaza (1994) ha propuesto la identificación de marca de filiación para el término eban.

El texto aquí estudiado se inscribe en la corta lista de inscripciones que presentan formularios complejos (Santa Perpètua de Mogoda, Fraga, Sinarcas, Liria), a la que se ha sumado la mencionada anteriormente de Civit. En ellas, a la estructura más frecuente y sencilla de nombre personal, se suceden cada vez en menor número a medida que aumenta su complejidad estructuras formulares en las que aparecen morfemas y elementos, en ocasiones abre- 
viados como ocurre en la estela recientemente publicada de Guissona (Guitart et alii, 1996). Uno de los elementos formulares típicamente funerarios es seltar, que en la estela de Nogueruelas aparece encabezando el texto seguido de la partícula ban y del morfema mi. Su posición inicial resulta del mayor interés, pues se trata de la primera ocasión en que ello sucede. En todos los casos documentados hasta ahora este elemento aparecía después de NP, seguido de $-\bar{m} i$ o de - ban. $\bar{m} i$. En consecuencia, éste es uno de los pocos textos sepulcrales que no van encabezados por NP, sino por un elemento cuyo significado se ha relacionado con el término "tumba" o similar. Nos encontramos, pues, con una estructura inédita hasta ahora en la epigrafía funeraria ibérica, en la que el elemento fundamental es el NP y como tal encabeza los textos, desde los más breves (Canet lo Roig: F.2.3) hasta los más extensos (Sinarcas: F.14.1).

Las consecuencias que pueden derivarse de este hecho son varias. En primer lugar, la estructura de los textos sepulcrales ibéricos no parece tan rígida en su encabezamiento, ya que puede comenzar con otro componente del texto (seltar) diferente al NP, tal y como sucede en la epigrafía latina; esto es, de nuevo, un factor de aproximación hacia este modelo. En segundo lugar, dicho componente puede ocupar una posición anterior o posterior al NP, siempre seguido de uno $(-\bar{m} i)$ o dos (-ban. $\bar{m} i)$ sufijos. Y en tercer lugar, resulta extraño que un texto funerario empiece con un substantivo cuyo significado se aproxime al del substantivo "tumba", pues en este caso se antepondría la denominación del monumento al nombre del difunto; por ello creemos que hay que abandonar la hipótesis de esta aproximación semántica para dicho elemento del formulario funerario. A continuación, en la segunda línea, debería figurar normalmente el nombre del difunto. El texto aparece aquí incompleto, pero la lectura más probable es bas[.]berunen $<\bar{m}>i$, en la que puede identificarse un nombre personal. Los antropónimos ibéricos presentan una estructura bimembre y están formados por dos elementos simples, en su mayoría bisilábicos ( $c f$. Untermann, 1987, 289290; MLH III 194-206). A este respecto, Untermann $(1979,63)$ y Siles $(1986,38)$ se han pronunciado contra la existencia en ibérico de NNP compuestos de tres miembros. La interpretación más sencilla es, pues, que nos encontremos ante una secuencia formada por NP $+e n+m i$, en la que el primero se componga de los elementos bas[.] y beŕun.

En la tercera línea, según la estructura más habitual en los textos sepulcrales, deberíamos encontrar- nos con un segundo NP que correspondería a la filiación. En bastobaśor vemos al menos la primera sílaba del primer elemento (bas-) del NP del difunto, que podría verse así repetido (MLH, III, § 603), según vemos en el nombre de dos jinetes de la Turma Salluitana (Criniti, 1970). De esta manera, por la posición que este segundo NP ocupa a continuación del del difunto y la relación entre ambos NNP, cabe pensar en la existencia de un vínculo familiar entre los dos personajes. Sin embargo, a continuación no encontramos el elemento - eban que frecuentemente acompaña a los NNP, para el que Velaza (1994) ha propuesto su identificación con la filiación. Falta, pues, la fórmula de filiación, el elemento clave para la identificación del segundo nombre como el del padre. La secuencia que aparece es, de nuevo, $\mathrm{NP}+e n+\bar{m} i$. La ausencia de la marca de filiación puede explicarse por la datación del texto en un momento en el que ésta todavía no se. ha implantado. El segundo NP debe corresponder, por tanto, al dedicante, que podría ser el mismo padre u otro.

La interpretación de las líneas 4-5 resulta más problemática por las lagunas en su lectura que impiden el reconocimiento de otros elementos que pueden aparecer en un texto funerario (parentesco, edad, verbo, fórmula de afecto, etc). Únicamente la repetición del sufijo $-\bar{m} i$ nos resulta familiar, pero no nos permite avanzar más en la comprensión de la estructura del texto.

En conclusión, la estructura del texto parece estar constituida por una fórmula sepulcral + NP (difunto) + NP (dedicante), seguidos de otro elemento cuya identidad se nos escapa.

Fórmula sepulcral (seltar) + sufijos (ban. $\bar{m} i)$

$\mathrm{NP}$ (bas[.]berun) + sufijos $(e n . \bar{m} i)$

NP (bastobaśor) + sufijos (en. $\bar{m} i)$

Elemento irreconocible + sufijo $(\bar{m} i)$

En relación con la tipología de los textos sepulcrales que de manera incipiente puede empezar a establecerse, el de la estela de Nogueruelas presenta una estructura compleja con un encabezamiento inédito, en el que está ausente el elemento -eban y también faltan abreviaturas como las identificadas en lápidas de Sagunto (F.11.11) y Guissona. Ambos elementos pudieron adoptarse en una época avanzada, posiblemente en los inicios del Imperio. Desde el punto de vista cronológico, estas consideraciones permiten establecer una mínima seriación que nos llevaría a situar el epígrafe de Nogueruelas en un momento anterior a la adopción de dichos elementos, y datarlo, por tanto, en época tardorrepublicana. 


\section{VALORACIONES FINALES}

La estela del Mas de Barberán constituye un ejemplo excepcional dentro de la plástica funeraria ibérica. Su interés reside, más que en su calidad estilística o en la técnica de labra, que no son en absoluto destacables, en la asociación de su morfología antropomorfa, con decoración figurada y la inscripción. El hallazgo, a su vez, del poblado y la necrópolis, donde seguramente se alzaría en su inicial ubicación y función, otorgan importancia a esta pieza al situarla en su ambiente arqueológico.

La figuración antropomorfa en un soporte pétreo con funcionalidad funeraria ha sido valorada, según las tesis de Almagro (1993, 1323), bien como la representación de una hipotética divinidad funeraria o, más bien, como la propia identificación de la figura del difunto, hecho relacionable tal vez con el desarrollo progresivo de detalles anatómicos y, en última instancia, con la existencia de otros monumentos funerarios ibéricos, heroizadores del difunto. Un simbolismo funerario, pero también un sentido conmemorativo se une en estas piezas, con particularidades propias. La ideología que proyecta la estela no es en absoluto episódica, puesto que está encarnada en la iconografía y el estilo de esta escultura.

En cuanto al disco-coraza, como hemos visto, a partir de la documentación disponible se desprende claramente que es un elemento de prestigio dentro de la panoplia ibérica. Pero además en el mundo antiguo, en general, las corazas son propias de sociedades de corte marcadamente aristocrático. La presencia de discos protectores es escasa en los ajuares de las necrópolis ibéricas, aunque está bien representada en la estatuaria antigua. La iconografía sobre piedra, según se está reconociendo paulatinamente, cumple una función precisa en la sociedad ibérica: la exaltación de las aristocracias. Esta representación, ya tardía a juzgar por el epígrafe, podría heredar o evocar algunas de las connotaciones propias de los conjuntos monumentales antiguos donde personajes masculinos van provistos de discos-coraza. A modo de hipótesis, la estela de Nogueruelas adopta un prototipo antiguo del imaginario ibérico. La imagen del guerrero con su arma protectora, anclada al soporte pétreo de la estela y unida al largo epígrafe inciso evoca valores aristocráticos enraizados en la sociedad ibérica.

A la tradición indígena representada por el monumento antropomorfo y el armamento se suma la presencia de la inscripción, cuya función funeraria puede deducirse por las características de la pieza. El deficiente estado de conservación del texto no permite más que una aproximación a la compren- sión de su estructura. Destaca el encabezamiento con el elemento seltar, que se asocia al contenido funerario, documentado por vez primera en esta posición, al que siguen dos antropónimos, posiblemente los del difunto y dedicante.

Respecto a su datación, aunque poblado y necrópolis tan sólo se conocen superficialmente, la ausencia de cerámicas imperiales como la terra sigillata itálica permite fijar un límite ante quem hacia la mitad del siglo I a.C. Esta datación se aviene con las propuestas para este tipo de monumentos, que se extiende desde el periodo iberorromano, en los siglos II-I a.C., hasta el siglo I d.C. (Mayer y Velaza, 1993). En concurrencia con esta propuesta se encuentra la posición que se le puede atribuir en el esbozo de seriación de los textos sepulcrales ibéricos, donde ocuparía un lugar anterior a la adopción de elementos típicamente romanos como la filiación y las abreviaturas, en lo que es una de las manifestaciones formales del cambio lingüístico (Arasa, 1997). En este sentido la estela de Nogueruelas se aproxima al grupo del Bajo Aragón, en el que destaca su carácter indígena, y se aleja de las manifestaciones epigráficas de los grandes núcleos urbanos como Emporiae, Tarraco y $\mathrm{Sa}$ guntum, en las que resulta patente la influencia romana. También la datación paleográfica nos sitúa de manera inequívoca en los siglos II-I a.C. En relación con la paleografía, Maluquer $(1968,67)$ atribuye la característica regularización de los grafemas que aparece en casi todos los textos epigráficos a la influencia del alfabeto monetal. Por su parte, Siles $(1986,21,39)$ la atribuye a la aproximación de las grafías indígenas a las letras capitales romanas, como un primer paso hacia la "latinización gráfica", con Emporiae y Saguntum como casos paradigmáticos, pero también a la tendencia hacia una escritura orientada cada vez más hacia la representación gráfica alfabética y el progresivo abandono del silabismo.

Desde el punto de vista de la distribución, su hallazgo se sitúa en una zona en la que este tipo de monumentos resultan poco frecuentes. Los más cercanos, también en tierras turolenses, hay que buscarlos en la Iglesuela del Cid, donde se conocen tres ejemplares (Arasa, 1983, 69-72: E.8.1-3). A mayor distancia podemos distinguir dos importantes grupos en tierras de Castellón y el Bajo Aragón, respectivamente. El de Castellón, con el que están relacionados los epígrafes de la Iglesuela del Cid, constituye uno de los focos más importantes de epígrafes funerarios, con un total de 13 textos: 3 en Canet lo Roig (F.2.1-3), 1 en Sant Mateu (F.2.4), 1 en Benassal (E.9.1), 1 en Les Coves de Vinromà (F.4.1), 3 en Alcalà de Xivert (F.3.1-3), 1 en Belllloc, 1 en Cabanes (F.5.1), 1 en Algimia de Almo- 
nacid (F.24.1) y el recientemente publicado de $\mathrm{La}$ Pobla Tornesa (Allepuz, 1996). Este grupo se encuentra situado geográficamente entre el del Bajo Aragón y el constituido por los epígrafes de la ciudad de Arse-Saguntum, con 17 textos sobre piedra en la ciudad (F.11.1-16), incluyendo el recientemente editado del teatro (Mayer y Velaza, 1996), y 8 más en el santuario próximo de La Muntanya Frontera (Fletcher y Silgo, 1987).

El grupo del Bajo Aragón, más alejado, es un foco mayoritariamente anepigráfico de unos treinta ejemplares que se extiende por los términos municipales de Alcañiz, Calaceite, Caspe, Cretas, Valdetormo, Vallderobles y Chiprana. Ninguna de las estelas ibéricas conocidas en tierras valencianas presenta motivos decorativos u ornamentales, y en ello radican las principales diferencias entre ambos grupos. En este sentido, cabe destacar que la estela de Nogueruelas presenta una mayor relación con el grupo del Bajo Aragón, no tanto en el aspecto formal como en la decoración.

En conclusión, nos encontramos ante un caso de perduración de elementos indígenas, tales como la propia morfología antropomorfa y la figuración del disco-coraza, en una época en la que han penetrado profundamente en la sociedad ibérica los estímulos escriptuarios romanos. Ambas formas de expresión, la iconográfica y la escriptuaria, fueron adoptadas en la representación funeraria de un guerrero para su heroización, en una fecha que podemos situar de manera aproximada entre la segunda mitad del siglo II y la primera del i a.C.

\section{BIBLIOGRAFÍA}

\section{Abreviaturas}

CIL II = Corpus Inscriptionum Latinarum: Hübner, 1892.

MLH = I, II, III Monumenta Linguarum Hispanicarum: Untermann, 1975, 1980, 1990.

Siles $=$ Siles, 1985 .

Velaza $=$ Velaza, 1991.

Albertini, E., 1935: Sculptures ibériques méconnues, Anuario de Cuerpo Facultativo de Archiveros, Bibliotecarios y Arqueólogos. Homenaje a Mélida, III, 215-221.

Almagro Basch, M., 1966: Las estelas decoradas del Suroeste Peninsular, Bibliotheca Praehistorica Hispanica, 8. Madrid.

Almagro BASCH, M., 1974: Nuevas estelas decora- das de la Península Ibérica, Miscelánea Arqueológica, 25० Aniversario de los Cursos de Ampurias (1947-1971), I, 5-39. Barcelona.

Almagro Gorbea, M., 1993: Les stèles anthropomorphes de la Péninsule ibérique, en: Briard, J. y Duval, A. (Eds.): Les représentations humaines $d u$ Néolithique à l'âge du fer. Actes du 115e Congrés National des Sociétés Savantes (Avignon, 1990), 123-139. Paris.

Almagro Gorbea, M., 1997: Lobos y ritos de iniciación en Iberia, en: Olmos, R. y Santos Velasco, J.A. (Eds.): Iconografía Ibérica. Iconografía itálica. Propuestas de interpretación y lectura. Coloquio Internacional (Roma, 1993). Serie Varia, 3, 103-127. Madrid.

Almarche, F., 1918: La antigua civilización ibérica en el reino de Valencia. Valencia.

Allepuz MarzÀ, X., 1996: Epigrafia ibèrica de la Balaguera (la Pobla Tornesa, Castelló), I Jornades Culturals a la Plana de L'Arc, 3-11. La Pobla Tornesa.

Aranegui, C.; Jodin, A.; Llobregat, E.; Roulllard, P. y UROZ, J., 1993: La nécropole ibérique de Cabezo Lucero. Guardamar del Segura. Alicante. CCV, 41. Madrid-Alacant.

Arasa i Gil, F., 1983: El Morrón del Cid (La Iglesuela del Cid), Revista Teruel, 70, 61-185.

Arasa I GIL, F., 1989: Una estela ibèrica de Bell-lloc (La Plana Alta), APL, XIX, Homenaje a D. Domingo Fletcher, III, 91-101.

Arasa I Gil, F., 1997: Aproximació a l'estudi del canvi lingüístic en el període ibero-romà (segles II-I a.C.), Arse. Número especial dedicado a Domingo Fletcher Valls, 28-29, 83-107.

Atrián JordAn, P., 1979: El yacimiento de Torre Gachero (Valderrobres) y las estelas ibéricas del Museo de Teruel, Revista Teruel, 61-62, 157-178.

Atrián, P.; Escriche, C.; Vicente, J. y Herce, A. I., 1980: Carta Arqueológica de España. Teruel, Teruel.

BAllester Tormo, I., 1942: Estela ibérica labrada, La labor del Servicio de Investigación Prehistórica y su museo en los años 1935 a 1939, 129132. Valencia.

BARCELÓ, J. A., 1988: Introducción al razonamiento estadístico aplicado a la arqueología: un análisis de las estelas antropomorfas de la Península ibérica, $T P, 45,51-85$.

Beltrán, M., 1996: Los Iberos en Aragón. Zaragoza.

Beltrán Martínez, A., 1953: De nuevo sobre el vasco-iberismo, Zephyrus, IV, 495-501.

Bianchi Bandinelli, R. y Giuliano, A., 1974: Los Etruscos y la Italia anterior a Roma, El Universo de las Formas. Madrid. 
BlánqueZ, J., 1993: Primeras aportaciones arqueológicas sobre la cronología de la escultura ibérica, en: Mangas, J., y Alvar, J. (Eds.): Homenaje a José María Blázquez, II, 85-108. Madrid.

Blázquez, J. M. y González Navarrete, J., 1985: The Phokaian Sculpture in Obulco in Southern Spain, AJA, 89, pp. 61-69.

Bosch GIMPERA, P., 1915-1920: Les investigacions de la cultura ibèrica al Baix Aragó, AIEC, VI, 650681.

Cabré Aguiló, J., 1915-1920: Esteles ibèriques ornamentades del Baix Aragó, AIEC, VI, Barcelona, 629-649.

CABré de Morán, Mª E., 1949: Los discos-coraza en los ajuares funerarios de la Edad del Hierro en la Península Ibérica, IV CASE, 186-190 (Elche, 1948). Cartagena.

Cortell, E.; Juan, J.; Llobregat, E.A.; Reig, C.; Sala, F. y Segura, J.M., 1992: La necrópolis ibérica de La Serreta. Resumen de la campaña de 1987, S.T.V., 89, Homenaje a E. Pla Ballester, 83-116.

Chenorkian, R., 1988: Les Armes metalliques dans l'Art Protohistorique de l'Occident Méditerraneen. Paris.

Criniti, N., 1970: L'epigrafe di Ausculum dei Gn. Pompeio Strabone. Milano.

DÉChelette, J., 1927: Manuel d'Archéologie Prehistorique, Celtique et Gallo-Romaine. IV. Second Age du Fer ou Époque de la Tène. Paris.

De JuliI, E., 1988: Gli Iapigi. Storia e Civiltà della Puglia preromana. Longanesi \& C. Col. Archeologia, 8. Milano.

Esteve i Gálvez, F., 1989: La lápida ibérica de Cabanes, APL, XIX, Homenaje a D. Domingo Fletcher, III, 103-116.

FERNÁNDEZ Fuster, L., 1951: Las estelas ibéricas del Bajo Aragón, Seminario de Arte Aragonés, III, 55 y ss.

Fletcher, D., 1965: La necrópolis de La Solivella (Alcalá de Chivert), T.V. SIP, 32.

Fletcher Valls, D., 1979: De nuevo sobre el signo ibérico Y, Varia, I, 183-189.

Fletcher Valls, D., 1985: Textos ibéricos del Museo de Prehistoria de Valencia, T.V. SIP, 81.

Fletcher Valls, D. y Giner Sospedra, V., 1974: Tres lápidas ibéricas de Canet lo Roig (Castellón), Boletín de la Sociedad Castellonense de Cultu$r a$, L, 138-156.

Fletcher, D. y Silgo, L., 1987: Repertorio de inscripciones ibéricas procedentes de Sagunto (Valencia), Arse, 22, 659-676.

Galán Domingo, E., 1993: Estelas, paisaje y territorio en el Bronce Final del Suroeste de la Península ibérica, Complutum, Extra 3.
GiménEZ Ortuño, Ll., 1988: Noticia sobre una nueva escultura ibérica: el thoracato ibérico de "La Losa" (Casas de Juan Nuñez, Albacete), Homenaje a Samuel de los Santos, 131-135. Madrid.

Gómez Moreno, M., 1949: Misceláneas, Historia, Arte, Arqueología. Madrid.

González Navarrete, J., 1987: Catálogo de la Escultura ibérica del Museo de Jaén. Jaén.

GRÜNHAGEN, W., 1976: Bemerkungen zum MinervaRelief und der Stadtmauer von Tarragona, M.M., 17, 209-250.

Guitart, J.; Pera, J.; Mayer, M. y Velaza, J., 1996: Noticia preliminar sobre una inscripción ibérica encontrada en Guissona (Lleida), La Hispania prerromana. Actas del VI Coloquio sobre lenguas y culturas prerromanas de la Península Ibérica, 163-170. Salamanca.

Hoz, J. de, 1983: Las lenguas y la epigrafía prerromanas de la Península Ibérica, Actas del VI Congreso Español de Estudios Clásicos, 351-396. Madrid.

HÜBNER, E., 1892: Corpus Inscriptionum Latinarum. Inscriptiones Hispaniae Latinae. Suplementum, II. Berlin.

IzQuierdo, Ma I., 1997: Pilares-estela ibéricos. Estudio de un tipo de monumento funerario aristocrático. Tesis doctoral inédita. Universitat de València.

IZQUIERDO, M. ${ }^{\mathrm{a}}$ I., 1998: Iberian Anthropomorphic steles - the examples from La Serrada (Ares de Maestre, Castellón) and Mas de Barberán (Nogueruelas, Teruel), Journal of Iberian Archaeology, $0,115-131$.

IZQUIERDO, $\mathrm{M}^{\mathrm{a}}$ I. (en prensa): Un lote de armas procedente de la necrópolis ibérica del Mas de Barberán (Nogueruelas, Teruel), Gladius.

IzQuiERdo, Ma I. y ARASA, F. (en prensa a): La imagen de la memoria. Antecedentes, tipología e iconografía de las estelas de época ibérica. Archivo de Prehistoria Levantina.

IzQuiERdo, $\mathrm{M}^{\mathrm{a}}$ I. y ARASA, F. (en prensa b): La estela ibérica de La Serrada (Ares del Maestre, Castellón), P.L.A.V.-Saguntum, 31.

Jacobsthal, P., 1969: Early Celtic Art. Oxford.

Jehasse, J. y Jehasse, L., 1973: La Nécropole préromaine d'Aléria (1960-1968), Gallia, XXV, Suppl. Paris.

KuRTZ, W.S., 1985: La coraza metálica la Europa protohistórica. B.A.E.A.A., núm. 21, 13-23.

KURTZ, W.S., 1991: Elementos etrusco-itálicos en el armamento ibérico. En: J. Remesal y O. Musso (coords.), 1991: La presencia de material etrusco en la Península Ibérica (Barcelona, 1990), 187196. Universitat de Barcelona. 
Lillo, P., 1986: Armas y utillaje entre los iberos, en: Mas, J. (Dir.), Historia de Cartagena, 537-584. Murcia.

López Monteagudo, G., 1983: La estela de Caspe y los pilares-estela ibéricos, AEspA, 56, 261-268.

Lucas, Ma R., Ruano, E. y SERrano, J., 1991: Escultura ibérica de Espejo (Córdoba): Hipótesis sobre su funcionalidad, Espacio, Tiempo y Forma, Serie II, $\mathrm{H}^{\mathrm{a}}$ Antigua, IV, 297-318.

MALuQuer DE Motes, J., 1968: Epigrafía prelatina de la Península Ibérica. Barcelona.

Marco Simón, F., 1974: Las estelas de tradición indígena del Museo de Teruel, Teruel, 52, 93-103.

Marco Simón, F., 1976: Nuevas estelas ibéricas de Alcañiz (Teruel), Pyrenae, 12, 73-90.

Marco Simón, F., 1978: Las estelas decoradas del convento Caesaraugustano y Cluniense, Caesaraugusta, 43-44.

Martín Bueno, M. A. y Pellicer, M., 1979-80: Nuevas estelas procedentes de Caspe (Zaragoza), Habis, 10-11, 401-420.

Maya González, J.L., 1977: Lérida Prehistórica. Cultura Ilerdense. Lérida.

MaYer, M. y VelazA, J., 1993: Epigrafía ibérica sobre soportes típicamente romanos, Lengua y cultura en la Hispania prerromana. Actas del V Coloquio sobre lenguas y culturas prerromanas de la Península Ibérica, 667-682. Salamanca.

Mayer, M. y Velaza, J., 1996: Una inscripción ibérica en el teatro de Sagunto, Studia Philologica Valentina, 1, 107-110.

Meseguer Folch, V. y Giner Sospeda, V., 1983: La necrópolis ibérica del Puig de Benicarló. Cuadernos de Historia y Arqueología de Benicarlo, 3.

Michelena, L., 1961: Comentarios en torno a la lengua ibérica, Zephyrus, XII, 5-23.

Michelena, L., 1976: Ibérico -EN, Actas del I Coloquio sobre Lenguas y Culturas Prerromanas de la Península Ibérica, 353-361. Salamanca.

Michelena, L., 1979: La langue ibère, Actas del II Coloquio sobre lenguas y culturas prerromanas de la Península Ibérica, 23-39. Salamanca.

Morote BarberÁ, J. G., 1981: Una estela de guerrero con espada de antenas en la necrópolis de Altea la Vella (Altea, Alicante), APL, XVI, 417-446.

Nava, M. L., 1980: Stele daunie I. Il Museo di Manfredonia. Firenze.

Nava, M. L., 1984: Le stele della Daunia, La civiltà di Dauni nel quadro del mondo italico, Atti del XIII Convegno di studi etruschi e italici, 163-187 (Manfredonia, 1980). Firenze.

Nebot CAlpe, N., 1991: Toponimia del Alto Mijares y del Alto Palancia. Estudio etimológico. Castellón.

Negueruela, I., 1990: Los monumentos escultóricos ibéricos del Cerrillo Blanco de Porcuna (Jaén). Estudio sobre su estructura interna, agrupamientos e interpretación. Jaén.

NICOLINI, G., 1969: Les bronzes figurés des sanctuaires ibériques. Paris.

Nieto Gallo, G., 1944: La necrópolis hispánica del Cabecico del Tesoro, Verdolay. Tercera Campaña de Excavaciones (octubre de 1942), BSEAA, IX, 191-196.

Oliver FoIX, A., 1978: Epigrafía ibérica de la provincia de Castellón, Cuadernos de Prehistoria y Arqueología Castellonenses, 5, 265-291.

Oliver FoIX, A., 1996: Las estelas monolíticas ibéricas, una aproximación a su problemática, Espacio, Tiempo y Forma, Serie I, Prehistoria y Arqueología, 235-238.

Olmos, R., 1997: Las incertidumbres de los lenguajes iconográficos: las páteras de plata ibéricas, en: Olmos, R. y Santos Velasco, J.A. (Eds.): 1997, Iconografía Ibérica. Iconografía itálica. Propuestas de interpretación y lectura. Coloquio Internacional (Roma, 1993). Serie Varia, 3, 91-102. Madrid.

Olmos, R. y CHAPA, T., 1997: Busto de varón hallado en Baza (Granada), en: Olmos, R. y Tortosa, T. (Eds.), 1997, La Dama de Elche. Lecturas desde la diversidad, 163-170. Colección Linx, núm. 2. Madrid.

Perales García, M. P., 1989: Introducción al Poblamiento Ibérico en Mora de Rubielos (Teruel), Monografías Arqueológicas del Seminario de Arqueología y Etnografías Turolenses, 2. Teruel.

Pontrandolfo, A.; Mugione, E. y Salomone, F., 1997: Alcuni esempi figurativi dell'Italia Antica, en Olmos, R. y Santos Velasco, J.A. (Eds.), Iconografía Ibérica. Iconografía itálica. Propuestas de interpretación y lectura. Coloquio Internacional (Roma, 1993), 283-318. Madrid.

Quesada, F., 1989: Armamento, guerra y sociedad en la necrópolis ibérica de El Cabecico del Tesoro, BAR IS, 502. Oxford.

QuesADA, F., 1994: Lanzas hincadas. Aristóteles y las estelas del Bajo Aragón, V Congreso de Estelas Funerarias, I, 361-369. Soria.

QuesadA, F., 1997: El armamento ibérico. Estudio tipológico, geográfico, funcional, social y simbólico de las armas en la cultura ibérica (siglos VII a.C.), Monographies instrumentum, 3. Montagna.

Quintanilla Niño, A., 1993: El vocalismo ibérico, Lengua y Cultura en la Hispania Prerromana, Actas del V Coloquio sobre Lenguas y Culturas Prerromanas de la Península Ibérica, 727-737. Salamanca. 
Ramos Fernández, R. y Ramos Molina, A. 1992: El monumento y el témenos del Parque de Elche. Elche.

Ramos Folqués, A., 1950: Hallazgos escultóricos de La Alcudia de Elche, AEspA, 81, 353-359.

Rodríguez RAmos, J., 1997: Primeras observaciones para una datación paleográfica de la escritura ibérica, AEspA, 70, 13-30.

RuANo, E., 1987: La escultura humana de piedra en el mundo ibérico. Madrid.

Siles, J., 1980: La inscripción de la Peña de las Majadas, Boletín de la Sociedad Castellonense de Cultura, LVI, 171-189.

SILES, J., 1981: Sobre el signo ibérico Y y los valores fonéticos que anota. Apuntes para una sistematización de las grafías de las nasales en la escritura ibérica, Emerita, XLIX, 75-96.

SILES, J., 1985: Léxico de inscripciones ibéricas. Madrid.

SiLes, J., 1986: Sobre la epigrafía ibérica, Epigrafía Hispánica de época romano-republicana, 17-42. Zaragoza.

Silgo Gauche, L., 1994: Léxico ibérico. Valencia.

Simón GómeZ, J. L., 1984: Compresión y distensión alpinas en la cadena ibérica litoral. Teruel.

TOVAR, A., 1949: Estudios sobre las primitivas lenguas hispánicas. Buenos Aires.

Tovar, A., 1951: Léxico de las inscripciones ibéricas (celtibérico e ibérico), Estudios dedicados a Menéndez Pidal, II, 273-323. Madrid.

Tovar, A., 1959: El Euskera y sus parientes. Madrid.

TOVAR, A., 1960: Lenguas prerromanas no indoeuropeas: testimonios antiguos, Enciclopedia Lingüística Hispánica, I, 5-26. Madrid.

Tovar, A., 1961: The ancient Languages of Spain and Portugal. New York.

Tovar, A., 1979: Notas lingüísticas sobre monedas ibéricas, Actas del II Coloquio sobre Lenguas y Culturas Prerromanas de la Península Ibérica, 473-489. Salamanca.

UntermanN, J., 1972: Ein neugefundener Steinaltar mit iberischer Inschrift aus Südfrankreich, Homenaje a A. Tovar, 465-468. Madrid.

Untermann, J., 1975: Monumenta Linguarum Hispanicarum. I. Die Munzlegenden. Wiesbaden.

UNTERMANN, J., 1979: Eingennamen auf Iberischen Inschriften, Actas del II Coloquio sobre Lenguas y Culturas Prerromanas de la Península Ibérica, 41-67. Salamanca.

Untermann, J., 1980: Monumenta Linguarum Hispanicarum. II. Die Iberischen Inschriften aus Südfrankreich. Wiesbaden.

Untermann, J., 1984a: Der Iberische Buchstabe Y, Navicula Tubingensis. Studia in Honorem Antonii Tovar, 378-381. Tübingen.

UNTERMANN, J., 1984b: Inscripciones sepulcrales ibéricas, Cuadernos de Prehistoria y Arqueología Castellonenses, 10, 111-119. Castellón.

UNTERMANN, J., 1987: Repertorio antroponímico ibérico, Archivo de Prehistoria Levantina, XVII, 289318. Valencia.

Untermann, J., 1990: Monumenta Linguarum Hispanicarum. III. Die Iberischen Inschriften aus Spanien. 2. Die Inschriften. Wiesbaden.

VALERI, V., 1993: Las nasales ibéricas, Lengua y Cultura en la Hispania Prerromana, Actas del V Coloquio sobre Lenguas y Culturas Prerromanas de la Península Ibérica, 739-746. Salamanca.

Velaza Frías, J., 1991: Léxico de inscripciones ibéricas (1976-1989). Barcelona.

VELAZA FRÍAS, J., 1993: Una nueva lápida ibérica procedente de Civit (Tarragona), Pyrenae, 24, 159-165.

Velaza Frías, J., 1994: Iberisch -eban, -teban, Zeitschrift für Papyrologie und Epigraphik, 104, 142150.

Velaza Frías, J., 1996a: Epigrafía y lengua ibéricas. Madrid.

Velaza Frías, J., 1996b: Epigrafía funeraria ibérica, Estudios de lenguas y epigrafía antiguas, 2, 251282. Valencia.

VentuRA, S., 1959: Excursiones al encuentro de la Historia. La cueva «Gallinera» y la «piedra» del Mas de Barberán, Cortes de Arenoso, 2, 6-7 y 29. 